\title{
Tests and Models of Hydraulic Concrete Material with High Strength
}

\author{
Yajun Wang \\ School of Maritime and Civil Engineering, Zhejiang Ocean University, Zhoushan 316000, China \\ Correspondence should be addressed to Yajun Wang; aegis68004@163.com
}

Received 19 November 2015; Revised 16 March 2016; Accepted 13 April 2016

Academic Editor: Gianfranco Palumbo

Copyright (C) 2016 Yajun Wang. This is an open access article distributed under the Creative Commons Attribution License, which permits unrestricted use, distribution, and reproduction in any medium, provided the original work is properly cited.

\begin{abstract}
The paper describes an investigation into the comprehensive sensitivities of Sino high strength hydraulic concrete to the addition levels of fly-ash powder and silica fume. Four fly-ash powder addition schemes $\left(100,120,140\right.$, and $\left.160 \mathrm{~kg} / \mathrm{m}^{3}\right)$ and four silica fume addition schemes $\left(12.5,17.5,22.5\right.$, and $\left.27.5 \mathrm{~kg} / \mathrm{m}^{3}\right)$ were considered, respectively. The curing ages' effects were incorporated in this study. The sensitive feedbacks, including creep development, temperature rise procedure, and strain-stress constitution, have been analyzed. The simulation and test results indicate that the Sino high strength hydraulic concrete, prepared by $140 \mathrm{~kg} / \mathrm{m}^{3} \mathrm{fly}-\mathrm{ash}$ powder and $22.5 \mathrm{~kg} / \mathrm{m}^{3}$ silica fume, gives the superb strength, durability, and creep stability.
\end{abstract}

\section{Introduction}

Sino hydraulic construction triggered up the heavy application of high strength and fully graded concrete that has been the predominant material for these monstrous structures during the past 30 years $[1,2]$. Meanwhile, the mechanicalphysical characteristics of the massive high strength hydraulic concrete (HSHC) controlled primarily these hydraulic structures' working behaviors $[3,4]$.

However, there is little work to study the comprehensive properties of Sino HSHC material of which the expected amount in the future is still above 6 hundred million $\mathrm{m}^{3}$ in China $[5,6]$.

The main philosophy for the potential-exploiting of HSHC is to optimize the mixture's constituents creatively in order to increase its strength and durability and reduce its creep and hydration heat generation (that can cause dreadful damage, fracture, etc.) as much as possible.

Some work paid close attention to the constituents' effects on the working behavior of the normal concrete. The aggregates could be treated by chemical process to strengthen its connection with the mortar binder [7]; the water curing activity for the aggregates has also been employed in most Sino concrete construction including the work in this paper.
Some supplement aggregates, such as furnace slag, were utilized in concrete material that showed distinct cost-advantage [8]; however, the vehement abrasion in the hydraulic environment may be a challenge against it.

Particularly, the study of the special concrete has been one hotspot of material science advances. Some specific additions in the concrete material were adopted and their mechanicalphysical effects were also studied. The thermal conductivity could be the key factor for the nuclear reactor concrete [9]; the application of magnetite aggregate was helpful for the thermal conductivity innovation. The pumice material was used to substitute the rock aggregates and the cost could be cut down effectively [10]; according to the relative study, the pumice aggregate concrete could get the maximally compressive strength up to $30 \mathrm{MPa}$ that met the requirements of the conventional concrete construction.

In terms of HSHC study, it is the crucial methodology to qualify the functions of its constituents so as to exploit optimally its potential capacity.

The internal addition method was employed in this paper to study the comprehensive sensitivities of Sino HSHC to the addition levels of silica fume and fly-ash powder. Namely, the cement powder was replaced by these agents directly and variably. 


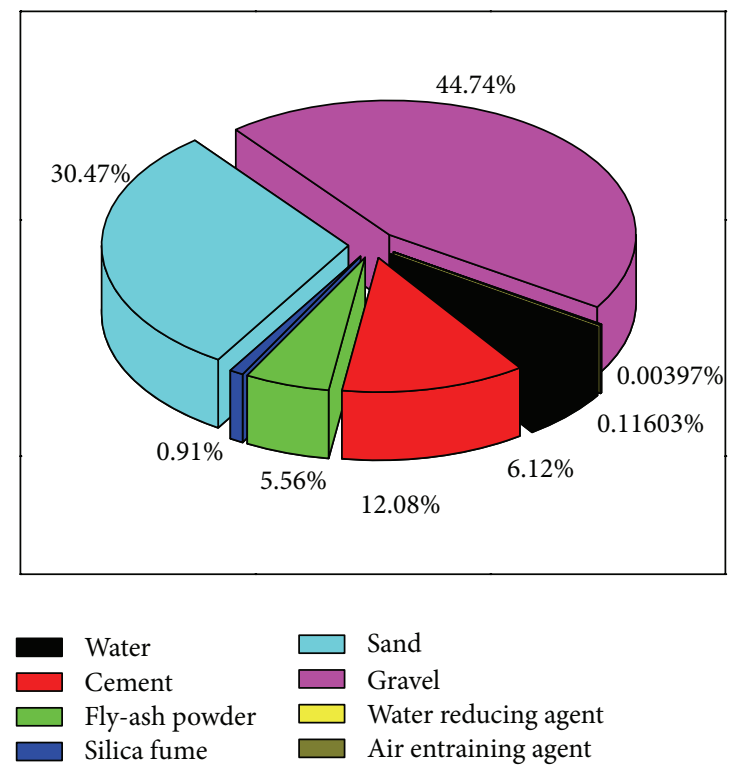

FIGURE 1: Standard constituents percentages of Sino high strength hydraulic concrete (with mass proportions).

In the present study, the well-grained silica fume and flyash powder (the level of their particles' sizes is $1 \times 10^{-2} \mathrm{~mm}$ ) were utilized with different addition schemes by mass $(12.5$, $17.5,22.5$, and $27.5 \mathrm{~kg} / \mathrm{m}^{3}$ for silica fume; $100,120,140$, and $160 \mathrm{~kg} / \mathrm{m}^{3}$ for fly-ash powder). Particularly, the curing ages were considered in detail in the thermodynamics and strainstress constitutive model.

The thermodynamic characteristics and strain-stress constitution were discussed in this study with the diverse addition schemes. Particularly, several updated models on the temperature rise procedure and the thermodynamic creep development as well as the stress path variation were established for HSHC whose properties can be then investigated more appropriately than by the conventional ones.

The second part of this paper stated the constituents' preparation and the samples' production as well as the experimental equipment and programs; the third part expressed the methodologies on the comprehensive tests that included the laboratory and the in situ ones; the fourth and fifth parts introduced the primary tests' results of thermodynamic characteristics and strain-stress constitutive model; the sixth part discussed in detail the systematical sensitivities of HSHC. With the diverse addition schemes of silica fume and fly-ash powder, the multimechanical-physical characteristics including the temperature rise procedure, the thermodynamic creep development, and the strength evolution of HSHC were investigated.

\section{Experimental Programs}

2.1. Material Constituents of Sino HSHC. We produced the target concrete material for our study in the State Key Laboratory of Hydroscience and Hydraulic Engineering of Tsinghua University. The original place for all the parental materials is the construction site in Southern-Western China where the gravel, sand, cement, and silica fume were collected. We designed the target concrete material's standard constituents percentages based on their mass proportions (Figure 1). The expected compressive strength of the target concrete material is above $40 \mathrm{MPa}$.

The information on the parental materials was offered based on their mass proportions.

Gravel and sand, as the aggregate constituents, were taken from the Jinshajiang River catchment (Figure 2). Gravel with the size range of 5-20 mm was excavated from the basalt layer of Jinshajiang mountain. River sand with the relative compaction value of 0.35 was collected from the valley bed $[11,12]$.

The cement producer in the study is XUANWEI Company in Southern-Western China. The cement powder (Figure 3 ) with grade 425 of Sino mainland standard is moderateheat one $[13,14]$.

The mixing water with $\mathrm{pH}$ of 7.0 is Northern China pure water and can be applied instantly for lives.

The fly-ash powder producer is HAICHUANG Company in Nantong city of Jiangsu province. Its average grain diameter is $0.045 \mathrm{~mm}$ (Figure 4). The content percentage of $\mathrm{SO}_{3}$ is $<3 \%$. As the crucial constituent of Sino high strength hydraulic concrete, it can help diminish effectively the hydration heat generation, in particular, during the early stage of massive concrete pouring procedure [15]. Our work will establish the qualified relation between the sound amount of fly-ash powder and the thermodynamic characteristics of Sino HSHC.

The silica fume producer is LANGTIAN Company of Sichuan province in Southern-Western China. Its average grain diameter is $0.074 \mathrm{~mm}$ (Figure 5). Its proper application, in spite of the small amount, is the critical study of massive 


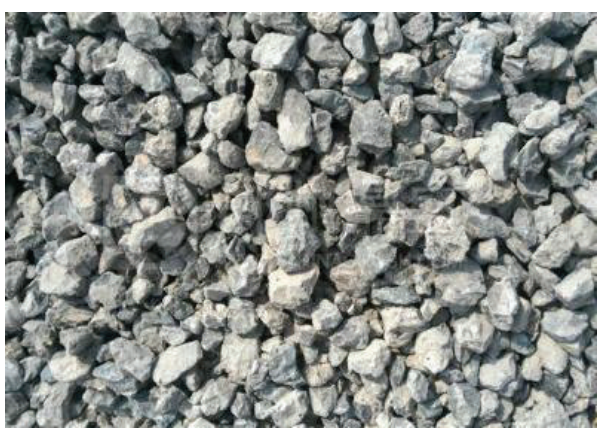

(a) Gravel

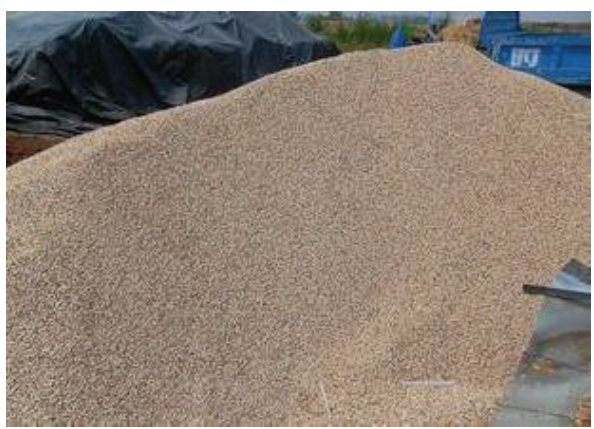

(b) Sand

Figure 2: Basalt gravel and river sand.

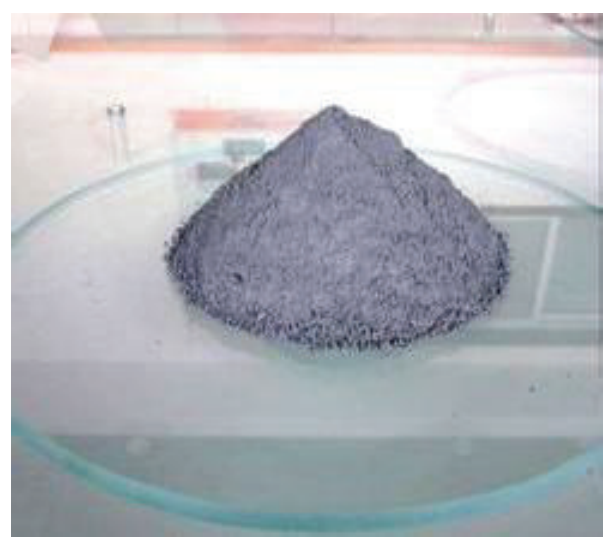

Figure 3: Cement powder.

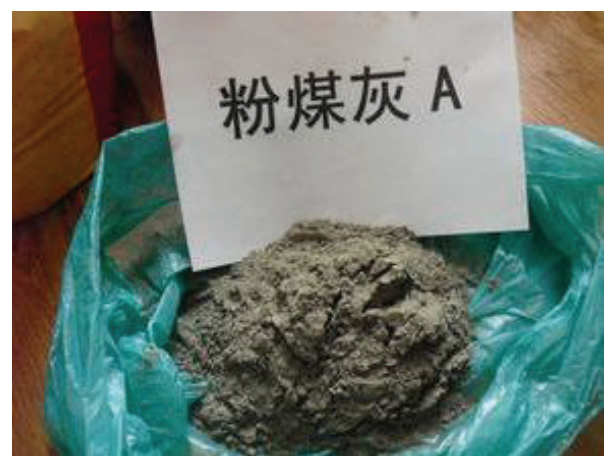

FIgURE 4: Fly-ash powder.

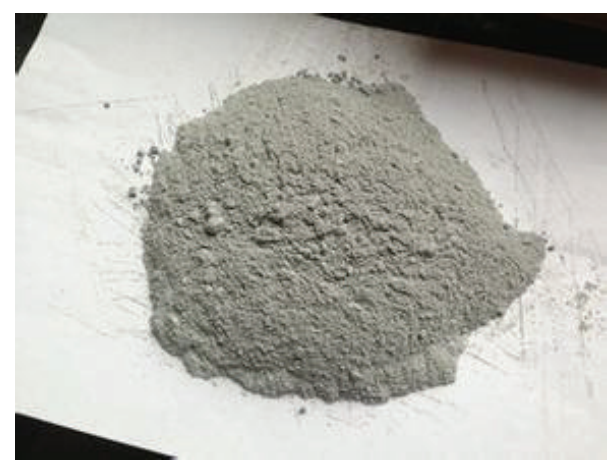

Figure 5: Silica fume. and high strength hydraulic concrete construction. This paper will study how the silica fume can strengthen the Sino HSHC material [16].

The water reducing agent is the twins agent for silica fume whose application will raise the water requirement and weaken the workability of Sino HSHC material. Hence, the application of water reducing agent can help decrease the water supplement [17]. The water reducing agent in this study is tripolycyanamide series and produced by XIANGBANG Company in Jiangsu province of China.

The heavy seeping pressure is another mortal threat against the Sino HSHC material. Air entraining agent can 


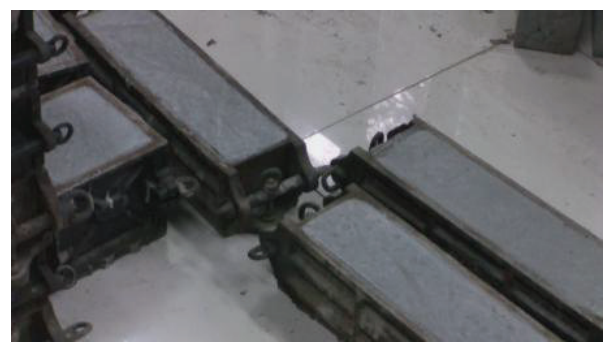

FIGURE 6: Concrete samples' modeling procedure.
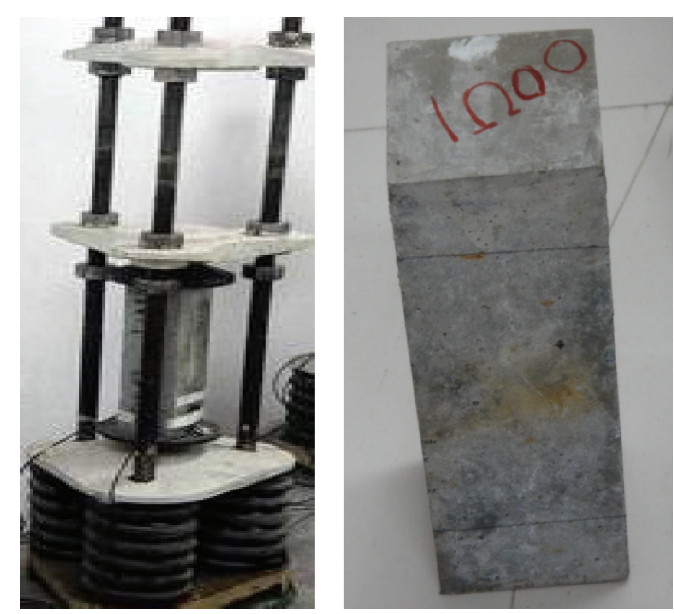

FIGURE 7: Creep loading test and standard concrete sample.

help reduce the original voids of concrete material and densify the massive concrete block. The air entraining agent in this paper is colophony series and produced by QICHENG Company in Shanghai.

2.2. Tests' Standards and Equipment. The constituents proportion design and concrete samples' modeling procedure obey mainly the Sino standards and refer partly to the American codes [13, 18-20].

According to the standard constituents percentages, the plastic concrete paste was produced in the mixer of which the type was JG244-2009 (maximal power $3 \mathrm{~kW}$; capacity $60 \mathrm{~L}$ ) produced by Jingwei Company of Hebei province in China. The standard mixing time was 30 minutes. The homogeneous paste then was poured into the normal moulds (Figure 6; standard dimension, i.e., length $\times$ width $\times$ height: $100 \mathrm{~mm} \times$ $100 \mathrm{~mm} \times 300 \mathrm{~mm}$ ) that were put on the vibroplatform for vibrating compaction (vibrating period 15 minutes; vibration frequency $50 \pm 3 \mathrm{~Hz}$; vibration amplitude $0.35 \mathrm{~mm}$ ).

These concrete samples were maintained in the curing chamber where the temperature and percentage relative humidity (RH) were $20 \pm 5^{\circ} \mathrm{C}$ and $95 \%$, respectively. The curing ages including 7 days and 28 days were different for these tests in this paper.

2.3. Thermodynamic Creep Tests. Figure 7 shows the standard concrete sample and creep loading test. The creep loading test instrument for Sino HSHC material was TXB-50 system

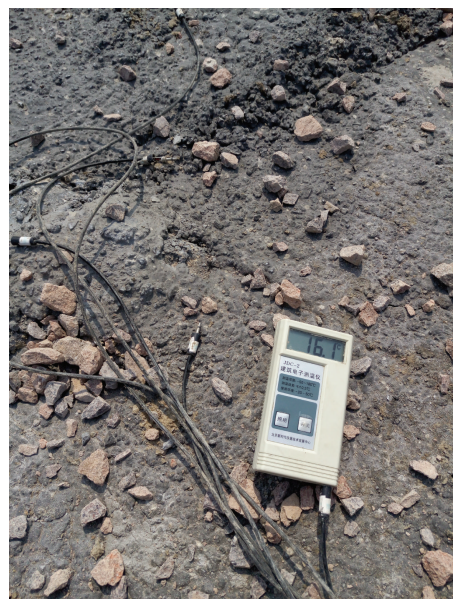

FIGURE 8: Temperature rise procedure test system.

produced by GANGYUAN Company in Tianjin. TXB-50 system (Figure 7) is spring instrument (maximal range $20 \mathrm{~mm}$; maximal tensile force $90 \mathrm{MPa}$ ).

2.4. Temperature Rise Procedure Tests. The system for temperature rise procedure test is automatic equipment JDC-2 that includes the data collector, sensors, and close circuit. The data of the whole temperature rise procedure can be collected continuously by them (Figure 8 ). 


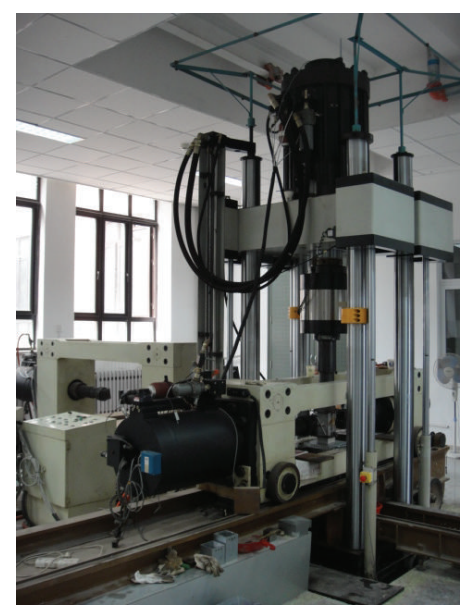

(a)

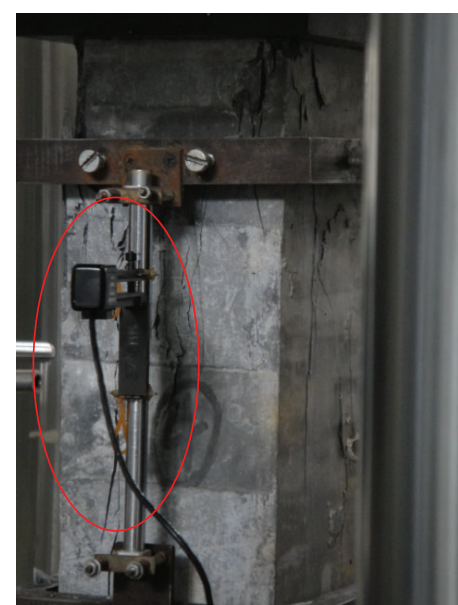

(b)

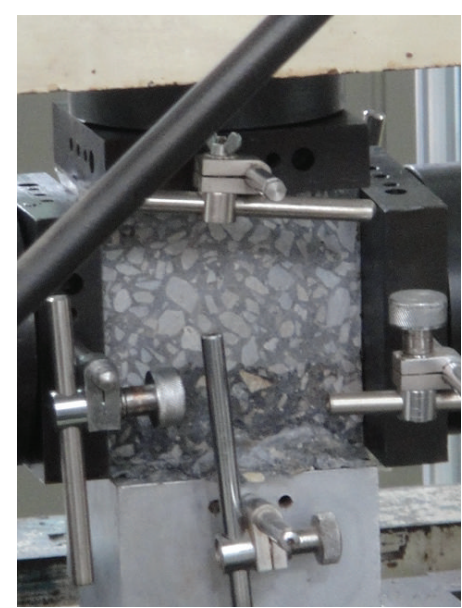

(c)

FIGURE 9: Multiaxial compressive loading tests.

2.5. Stress Characteristics Tests. Multiaxial compressive loading tests were realized with American Instron-8508 multiaxial loading system by which we simulated physically the whole multiaxial loading procedures of the target material (Figure 9). The maximal compressive force of Instron-8508 is $1 \mathrm{MN}$. The maximal strokes for vertical and horizontal axis are $900 \mathrm{~mm}$ and $750 \mathrm{~mm}$, respectively. The tensiometers (the marked area in Figure 9) are the key supplementary units in these tests to help get the complete stress-strain constitutive curves.

2.6. Systematic Curing Activities. Temperature rise procedure tests were implemented in the construction site. In order to realize the standard curing conditions, the systematic curing activities (Figure 10) were applied, including regular sprinkling; insulation blanket, board, and painting installation; water cooling pipe nets layout; full-time temperature monitoring.

\section{Proposed Methodologies}

3.1. Thermodynamic Creep Tests. As for the concrete samples with age of 7 days or 28 days, the eventual creep loading duration increment is 200 days that is the generally accepted standard of the concrete creep loading test in Sino mainland. The creep loading tests were applied in the specific chamber where the temperature was kept at $20 \pm 5^{\circ} \mathrm{C}$ and $\mathrm{RH}$ was above $75 \%$. The creep loading ages include $3,7,10,15,30,45,60$, $90,120,150$, and 200 days. The standard concrete samples were loaded with one incremental force (i.e., compensating force) at the end of every age and the strain induced by the incremental force was $10^{-5}$.

3.2. Temperature Rise Procedure Tests. The temperature rise procedure tests were implemented in one arch dam construction site of Sichuan province in Southern-Western China. The local average temperature during the test was $15^{\circ} \mathrm{C}$ and
RH was above $85 \%$. The tests began as soon as the concrete paste was set and the total age of the test was 90 days. The temperature sensors were eternally embedded in the HSHC paste. The full-time engineers, after the tests, will monitor the temperature evolution during the whole working period of the hydraulic structure.

3.3. Stress Characteristics Tests. Multiaxial compressive loading tests include uniaxial and biaxial compressive loading cases (Figure 9(b) was the uniaxial case; Figure 9(c) was the biaxial case). The multiaxial compressive loading tests adopted strain controlling technique. The strain velocity was $2 \times 10^{-4} /$ minute for the uniaxial compressive loading case. The vertical and horizontal axial strain velocities for the biaxial case were $1 \times 10^{-4} /$ minute and $5 \times 10^{-5} /$ minute, respectively. The temperature and $\mathrm{RH}$ during the tests were kept at $15 \pm 5^{\circ} \mathrm{C}$ and $50 \%$. The standard concrete samples were loaded after 28 days with standard curing activities.

3.4. Sensitivity Tests. Based on the standard constituents percentages of Sino HSHC material, how will the addition levels of fly-ash powder and silica fume affect HSHC's working behavior and comprehensive characteristics including thermodynamics, temperature rise procedure, and strainstress constitutions? We will study these comprehensive sensitivities on Sino high strength hydraulic concrete material.

\section{Thermodynamic Characteristics on High Strength Hydraulic Concrete}

The record of gravity dam with maximal concrete consumption is kept by Three Gorges gravity dam that has devoured 28,000 thousand $\mathrm{m}^{3}$ concrete material whose construction period lasted for 18 years. In the next decade, there will come more than 20 monstrous dams to be launched in Sino mainland and their construction period may occupy half of this century. During just this lengthy construction period, 


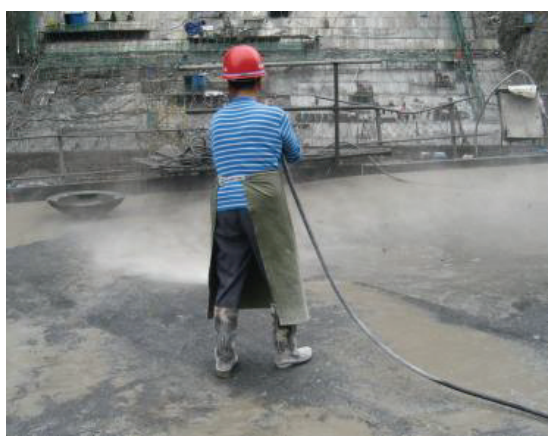

(a) Concrete surface sprinkling

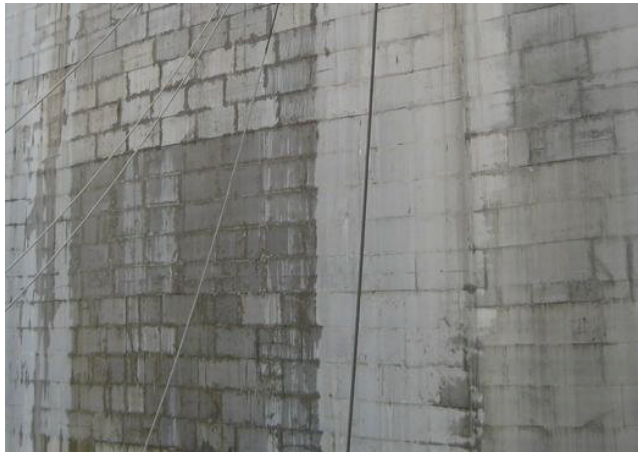

(c) Insulation board

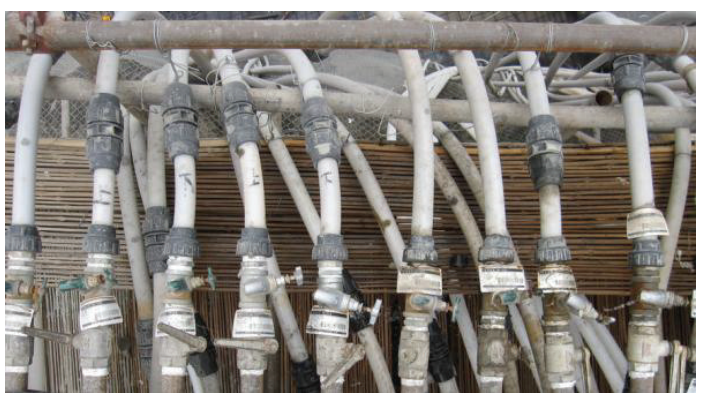

(e) Water cooling pipes nets

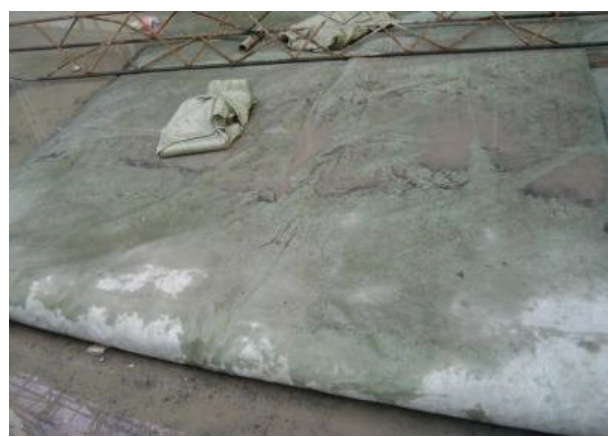

(b) Insulation blanket

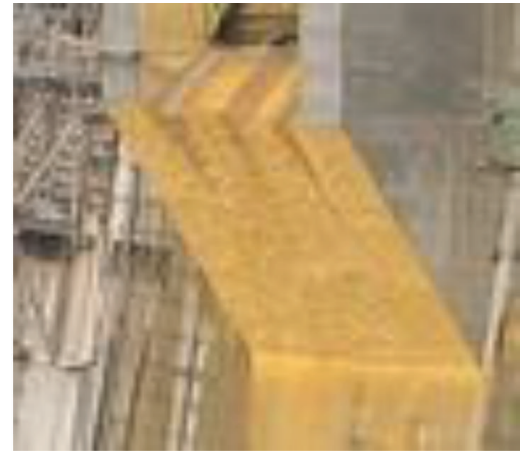

(d) Insulation painting

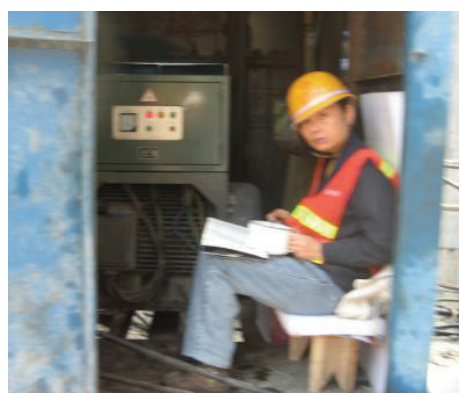

(f) Full-time engineer for temperature monitor

FIGURE 10: Systematic curing activities.

the massive concrete block will generate the ghastly amount of hydration heat that can split easily these hydraulic monsters [21]. Particularly, these colossal structures may be destroyed absolutely if the temperature cracks cannot be controlled properly $[22,23]$. Therefore, the quantification on Sino HSHC material's thermodynamic characteristics is the key shield against the hazardous thermodamage development.

The achievement of effective simulation models is the crucial approach for the quantification on Sino HSHC material's thermodynamic characteristics. The models should help engineers to ascertain the thermodynamic creep development and dynamic temperature rise procedure.

In terms of the thermodynamic creep models, they should be able to compute the recoverable creep and unrecoverable creep, respectively. Most cases of Sino hydraulic construction show that both the recoverable creep and unrecoverable creep accumulation are the lurking peril for temperature cracks development of massive hydraulic structures.

Figure 11 shows the distribution of temperature creep cracks of some typical Sino super dams that include arch dams and gravity ones with height over $150 \mathrm{~m}$. Chinese engineers and researchers adopted the compound exponential model (i.e., the referred model) in the past to realize the thermodynamic creep calculation:

$$
\begin{aligned}
C(t, \tau)= & {\left[A_{0}+A_{1} \tau^{\left(-A_{2}\right)}\right]\left[1-e^{-m_{1}(t-\tau)}\right] } \\
& +\left[B_{0}+B_{1} \tau^{\left(-B_{2}\right)}\right]\left[1-e^{-m_{2}(t-\tau)}\right] \\
& +D e^{\left(-m_{3} \tau\right)}\left[1-e^{-m_{3}(t-\tau)}\right],
\end{aligned}
$$




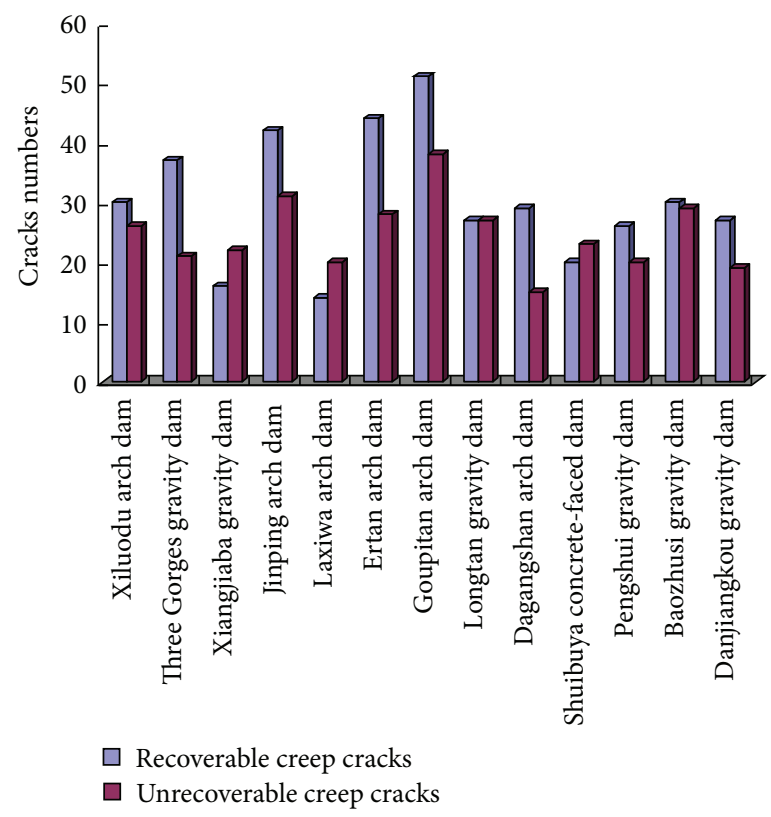

FIGURE 11: Temperature creep cracks development of Sino dams.

where $C(t, \tau)$ represents the thermodynamic creep values; $\tau$ denotes the static age from the curing start point; $t$ refers to the total age that includes the static age and loading period; $A_{0}, A_{1}, A_{2}, B_{0}, B_{1}, B_{2}, m_{1}$, and $m_{2}$ are the fitting parameters to calculate the recoverable creep of high strength hydraulic concrete material; $D$ and $m_{3}$ are the fitting parameters to calculate the unrecoverable creep; $t-\tau$ is the loading duration increment.

The philosophy of thermodynamic creep calculation is to quantify the recoverable creep and unrecoverable creep, respectively. The hydraulic application experiences told us that both of them could create temperature creep cracks, but they played different roles in different stages.

Based on the standard constituents percentages, the creep loading test and numerical simulation results are shown in Tables 1 and 2 .

It can be deduced that the recoverable creep will develop in the early stage of concrete material construction. Although this period is short one, the time accumulation gradient of recoverable creep development is very wild and reaches 0.21 $\times 10^{-6} / \mathrm{MPa}$ /day. Many mortal temperature cracks may be generated at the stage. On the contrary, the unrecoverable creep development is a long period, but its time accumulation gradient is only $0.009 \times 10^{-6} / \mathrm{MPa} /$ day. Surely, the lower time accumulation gradient of unrecoverable creep development does not mean the lower probability. There are still many temperature cracks cases caused by it according to Figure 11.

This paper established a concise model to simulate numerically the hybrid creep development of Sino high strength hydraulic concrete as the following equation:

$$
C(t, \tau)=\sum_{i=1}^{2} \Phi_{i}(\tau)\left[1-e^{-\eta_{i}(\tau)(t-\tau)^{\beta_{i}}}\right],
$$

where $\Phi_{i}$ is the creep coordinate functions; the model can simulate the recoverable or unrecoverable creep development when $i=1$ or $i=2$, respectively:

$$
\begin{aligned}
& \Phi_{1}(\tau)=\phi_{0_{\mid 1}}+\phi_{1_{\mid 1}} \tau^{-\alpha_{1}}, \\
& \Phi_{2}(\tau)=\varsigma e^{\left(-\alpha_{2} \tau\right)} .
\end{aligned}
$$

$\eta_{i}$ in (2) is defined as a loading duration function:

$$
\begin{aligned}
& \eta_{1}(\tau)=\delta_{0_{\mid 1}}+\delta_{1_{\mid 1}} \tau^{\vartheta_{1}}, \\
& \eta_{2}(\tau)=\delta_{0_{\mid 2}} .
\end{aligned}
$$

Based on the standard constituents percentages and (2), the comparisons of the creep loading test data and numerical simulation results are showed in Tables 3 and 4. Particularly, the longer the curing time is, the lower the parameters' values of $\eta_{1}$ are.

According to this model, the curing activities will have no effects theoretically over the creep development when the curing age exceeds loading duration increment of recoverable creep. Then, $\eta_{2}$ will be a constant one. Therefore, our study is very important because it can optimize basically the constitutive constituents of material by which the creep development of Sino HSHC can be controlled rationally.

Meanwhile, the comparisons between the numerical simulation results of (1) and (2) indicate clearly that the model of this paper has higher accuracy than the referred model (Tables 1-4 and Figure 12).

The hydration heat discharge of massive concrete material is the intrinsic trigger for temperature creep cracks of hydraulic structures. Hence, the proper calculation of hydration heat discharge is helpful for the precise assessment 
TABLE 1: Creep loading test data and numerical simulation results of referred model, sample's age: 7 days.

\begin{tabular}{|c|c|c|c|c|c|c|c|c|c|}
\hline \multirow{2}{*}{$\begin{array}{l}\text { Loading } \\
\text { duration } \\
\text { increment for } \\
\text { recoverable } \\
\text { creep/days } \\
3\end{array}$} & \multirow{2}{*}{$\begin{array}{c}\begin{array}{c}\text { Recoverable } \\
\text { creep } \\
\text { value } / 10^{-6} / \mathrm{MPa}\end{array} \\
4\end{array}$} & \multicolumn{2}{|c|}{ Fitting parameters } & \multirow{2}{*}{$\begin{array}{c}\begin{array}{c}\text { Fitting } \\
\text { creep values }\end{array} \\
4.2\end{array}$} & \multirow{2}{*}{$\begin{array}{l}\begin{array}{c}\text { Loading } \\
\text { duration }\end{array} \\
\text { increment for } \\
\text { unrecoverable } \\
\text { creep/days }\end{array}$} & \multirow{2}{*}{$\begin{array}{c}\begin{array}{c}\text { Unrecoverable } \\
\text { creep } \\
\text { value } / 10^{-6} / \mathrm{MPa}\end{array} \\
13.1\end{array}$} & \multicolumn{2}{|c|}{ Fitting parameters } & \multirow{2}{*}{$\begin{array}{c}\begin{array}{c}\text { Fitting creep } \\
\text { values }\end{array} \\
12.9\end{array}$} \\
\hline & & $A_{0}$ & 1.99 & & & & $D$ & 17.31437 & \\
\hline 7 & 6.9 & $A_{1}$ & 19.81 & 6.3 & 120 & 13.7 & $m_{3}$ & 0.02545 & 13.1 \\
\hline 10 & 8.2 & $A_{2}$ & 0.703 & 8.5 & 150 & 14.1 & & & 13.2 \\
\hline 15 & 9.1 & $B_{0}$ & 3.97 & 8.8 & 200 & 14.5 & & & 13.9 \\
\hline 30 & 10.4 & $B_{1}$ & 11.89 & 9.8 & & & & & \\
\hline 45 & 11.3 & $B_{2}$ & 1.495 & 10.9 & & & & & \\
\hline \multirow[t]{2}{*}{60} & 12.1 & $m_{1}$ & 0.0892 & 12.5 & & & & & \\
\hline & & $m_{2}$ & 0.10801 & & & & & & \\
\hline
\end{tabular}

TABLE 2: Creep loading test data and numerical simulation results of referred model, sample's age: 28 days.

\begin{tabular}{|c|c|c|c|c|c|c|c|c|c|}
\hline $\begin{array}{l}\text { Loading } \\
\text { duration } \\
\text { increment for } \\
\text { recoverable } \\
\text { creep/days }\end{array}$ & $\begin{array}{c}\text { Recoverable } \\
\text { creep } \\
\text { value } / 10^{-6} / \mathrm{MPa}\end{array}$ & Fitting $\mathrm{p}$ & parameters & $\begin{array}{c}\text { Fitting } \\
\text { creep values }\end{array}$ & $\begin{array}{c}\text { Loading } \\
\text { duration } \\
\text { increment for } \\
\text { unrecoverable } \\
\text { creep/days }\end{array}$ & $\begin{array}{c}\text { Unrecoverable } \\
\text { creep } \\
\text { value } / 10^{-6} / \mathrm{MPa}\end{array}$ & \multicolumn{2}{|c|}{ Fitting parameters } & \multirow{2}{*}{$\begin{array}{c}\begin{array}{c}\text { Fitting creep } \\
\text { values }\end{array} \\
10.2\end{array}$} \\
\hline 3 & 3.5 & $A_{0}$ & 2 & 3.1 & 90 & 9.9 & $D$ & 20 & \\
\hline 7 & 5.1 & $A_{1}$ & 18 & 5.4 & 120 & 10.9 & $m_{3}$ & 0.01813 & 11.1 \\
\hline 10 & 5.7 & $A_{2}$ & 0.55 & 5.9 & 150 & 11.3 & & & 11.7 \\
\hline 15 & 6.1 & $B_{0}$ & 3 & 6.5 & 200 & 11.9 & & & 12.4 \\
\hline 30 & 7.4 & $B_{1}$ & 10 & 7 & & & & & \\
\hline 45 & 8 & $B_{2}$ & 0.8 & 7.6 & & & & & \\
\hline \multirow[t]{2}{*}{60} & 8.8 & $m_{1}$ & 0.06 & 9.3 & & & & & \\
\hline & & $m_{2}$ & 0.2 & & & & & & \\
\hline
\end{tabular}

TABLE 3: Creep loading test data and numerical simulation results of this paper's model, sample's age: 7 days.

\begin{tabular}{|c|c|c|c|c|c|c|c|c|c|}
\hline $\begin{array}{l}\text { Loading } \\
\text { duration } \\
\text { increment for } \\
\text { recoverable } \\
\text { creep/days }\end{array}$ & $\begin{array}{c}\text { Recoverable } \\
\text { creep } \\
\text { value } / 10^{-6} / \mathrm{MPa}\end{array}$ & Fitting $\mathrm{p}$ & parameters & $\begin{array}{c}\text { Fitting creep } \\
\text { values }\end{array}$ & $\begin{array}{c}\text { Loading } \\
\text { duration } \\
\text { increment for } \\
\text { unrecoverable } \\
\text { creep/days }\end{array}$ & $\begin{array}{c}\text { Unrecoverable } \\
\text { creep } \\
\text { value } / 10^{-6} / \mathrm{MPa}\end{array}$ & Fitting $\mathrm{p}$ & arameters & $\begin{array}{c}\text { Fitting creep } \\
\text { values }\end{array}$ \\
\hline 3 & 4 & $\phi_{0_{\mid 1}}$ & 2.17 & 3.9 & 90 & 13.1 & $\varsigma$ & 21.4 & 13.2 \\
\hline 7 & 6.9 & $\phi_{1_{\mid 1}}$ & 23.5 & 6.7 & 120 & 13.7 & $\alpha_{2}$ & 0.152 & 13.5 \\
\hline 10 & 8.2 & $\alpha_{1}$ & 0.323 & 8.1 & 150 & 14.1 & $\delta_{0_{\mid 2}}$ & 0.274 & 13.9 \\
\hline 15 & 9.1 & $\delta_{0_{\mid 1}}$ & 2.835 & 9 & 200 & 14.5 & $\beta_{2}$ & 0.0395 & 14.6 \\
\hline 30 & 10.4 & $\delta_{1_{\mid 1}}$ & 19.84 & 10.2 & & & & & \\
\hline 45 & 11.3 & $\vartheta_{1}$ & 0.27 & 11.2 & & & & & \\
\hline 60 & 12.1 & $\beta_{1}$ & 0.0136 & 12 & & & & & \\
\hline
\end{tabular}


TABLE 4: Creep loading test data and numerical simulation results of this paper's model, sample's age: 28 days.

\begin{tabular}{|c|c|c|c|c|c|c|c|c|c|}
\hline $\begin{array}{l}\text { Loading } \\
\text { duration } \\
\text { increment for } \\
\text { recoverable } \\
\text { creep/days }\end{array}$ & $\begin{array}{c}\text { Recoverable } \\
\text { creep } \\
\text { value } / 10^{-6} / \mathrm{MPa}\end{array}$ & Fitted pa & arameters & $\begin{array}{c}\text { Fitting creep } \\
\text { values }\end{array}$ & $\begin{array}{l}\text { Loading } \\
\text { duration } \\
\text { increment for } \\
\text { unrecoverable } \\
\text { creep/days }\end{array}$ & $\begin{array}{c}\text { Unrecoverable } \\
\text { creep } \\
\text { value } / 10^{-6} / \mathrm{MPa}\end{array}$ & \multicolumn{2}{|c|}{ Fitted parameters } & $\begin{array}{c}\text { Fitting creep } \\
\text { values }\end{array}$ \\
\hline 3 & 3.5 & $\phi_{0_{\mid 1}}$ & 3.06 & 3.7 & 90 & 9.9 & $\varsigma$ & 25.3 & 9.8 \\
\hline 7 & 5.1 & $\phi_{1_{\mid 1}}$ & 22.6 & 5 & 120 & 10.9 & $\alpha_{2}$ & 0.126 & 10.7 \\
\hline 10 & 5.7 & $\alpha_{1}$ & 0.221 & 5.6 & 150 & 11.3 & $\delta_{0_{\mid 2}}$ & 0.061 & 11.1 \\
\hline 15 & 6.1 & $\delta_{0_{\mid 1}}$ & 2.177 & 6.3 & 200 & 11.9 & $\beta_{2}$ & 0.0171 & 12 \\
\hline 30 & 7.4 & $\delta_{1_{\mid 1}}$ & 14.62 & 7.5 & & & & & \\
\hline 45 & 8 & $\vartheta_{1}$ & 0.15 & 8.1 & & & & & \\
\hline 60 & 8.8 & $\beta_{1}$ & 0.0081 & 8.7 & & & & & \\
\hline
\end{tabular}

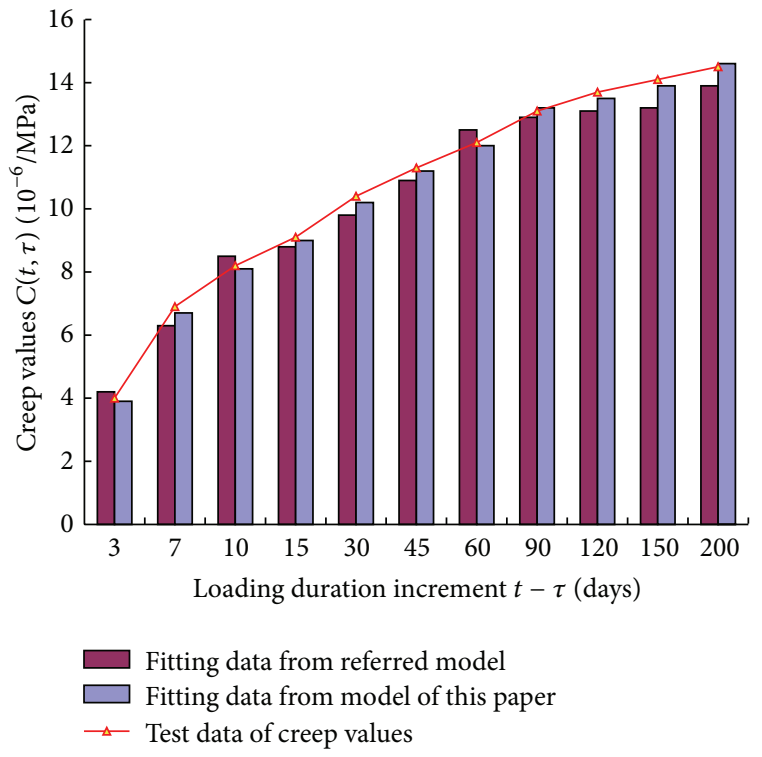

(a) Sample's age: 7 days

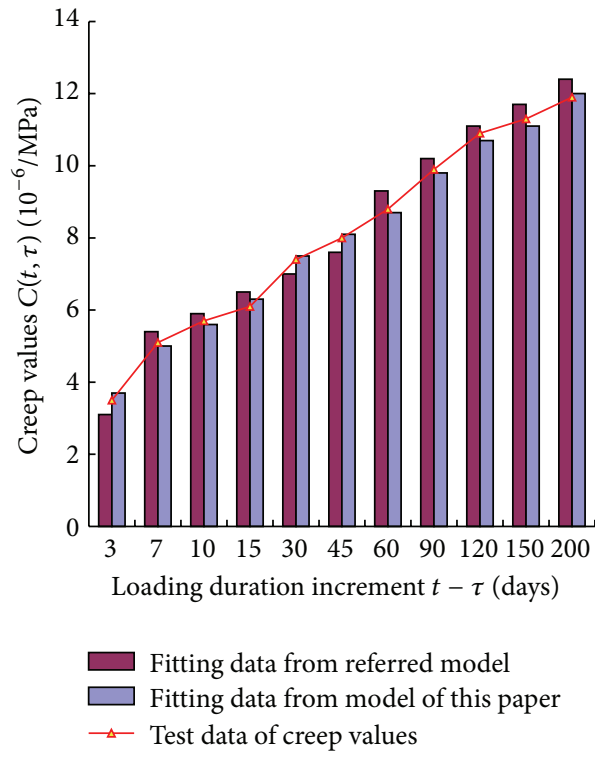

(b) Sample's age: 28 days

FIGURE 12: Comparisons of simulation accuracy of thermodynamic creep models.

of hydraulic structures' thermodynamic characteristics. The temperature rise model was adopted in this paper to qualify the dynamic procedure of massive concrete material's hydration heat discharge.

Here are four conventional temperature rise models [24], namely, power-exponential composite model (see (5)), hyperbolic model (see (6)), single-exponential model (see (7)), and double-exponential model (see (8)). One has

$$
\begin{aligned}
& T=T_{0}\left(1-e^{-a t^{b}}\right), \\
& T=\frac{28 t}{t+2.58},
\end{aligned}
$$

$$
\begin{aligned}
& T=T_{0}\left(1-e^{-a t}\right), \\
& T=T_{e}\left(1-e^{-c t}\right)+T_{l}\left(1-e^{-d t}\right),
\end{aligned}
$$

where $T$ is the temperature rise variable; $T_{0}$ is the ultimate temperature rise value; $T_{e}$ is the early stage temperature rise value; $T_{l}$ is the mature temperature rise value; $a, b, c$, and $d$ are the test parameters. As for Sino high strength hydraulic concrete material whose compressive strength is above $40 \mathrm{MPa}, T_{0}=26.4, T_{e}=5.4, T_{l}=25.4, a=0.252$, $b=0.883, c=0.005$, and $d=0.252$.

However, the hydration heat discharge of massive concrete material has close relation with the constitutive 
TABLE 5: Simulation values of the constitutive parameters.

\begin{tabular}{lcccccc}
\hline$\varepsilon_{f}$ & $\omega_{1}$ & $\omega_{2}$ & $\omega_{1}$ & $\omega_{2}$ & $v$ & $E_{\tau} / \mathrm{MPa}$ \\
\hline $1.23 \times 10^{-3}$ & $1.57 \times 10^{-1}$ & $8.43 \times 10^{-1}$ & 5.39 & 1.66 & 3.47 & $5.58 \times 10^{4}$ \\
\hline
\end{tabular}

constituents of material. Hence, the temperature rise model should incorporate the material's physical effects. At least, the proper model should consider the concrete material's sensitivity to its constituents. We established one updated hyperbolic model that will be introduced in the discussion.

\section{Stress Characteristics on High Strength Hydraulic Concrete}

Most cases of hydraulic concrete structures failure during the operating period were caused by diverse stress overloading conditions [25, 26]. Particularly, the stress states of the massive hydraulic structures are so complicated that the attempt to establish one generalized model will often fail. We will study the targeted stress characteristics of Sino HSHC material and express its stress development behaviors.

Stress-strain constitutive model plays the primary role in translating concrete material's mechanical behavior [27]. In China, the generally accepted stress-strain constitutive model for concrete material is the bisection nonlinear model which can be expressed as

$$
\sigma= \begin{cases}{\left[1-\omega_{1}\left(\frac{\varepsilon}{\varepsilon_{f}}\right)^{\omega_{1}}\right] E_{\tau} \varepsilon} & 0 \leq \varepsilon \leq \varepsilon_{f} \\ {\left[\frac{\omega_{2}}{v\left(\varepsilon / \varepsilon_{f}-1\right)^{\omega_{2}}+\varepsilon / \varepsilon_{f}}\right] E_{\tau} \varepsilon} & \varepsilon>\varepsilon_{f},\end{cases}
$$

where $\sigma$ and $\varepsilon$ are the stress and strain variable, respectively; $\varepsilon_{f}$ is the peak strain under compressive loading case; $\oplus_{1}, \emptyset_{2}$, and $\omega_{1}$ are the concrete material parameters that indicate the continuousness of the bisection nonlinear model at $\varepsilon_{f} ; \omega_{2}$ and $v$ are the shape parameters that indicate the geometrical characteristics of the nonlinear strain-stress curves; $E_{\tau}$ is the nominal modulus.

In terms of standard constituents percentages of Sino HSHC material, the simulation values of these constitutive parameters are shown in Table 5.

\section{Discussion}

The study on comprehensive characteristics sensitivity is valuable for ascertaining the effects of constituents' application in Sino high strength hydraulic concrete material. The comprehensively sensitive study in this paper was based on internal addition method. Namely, the cement powder was replaced by these agents directly and variably [28-30].

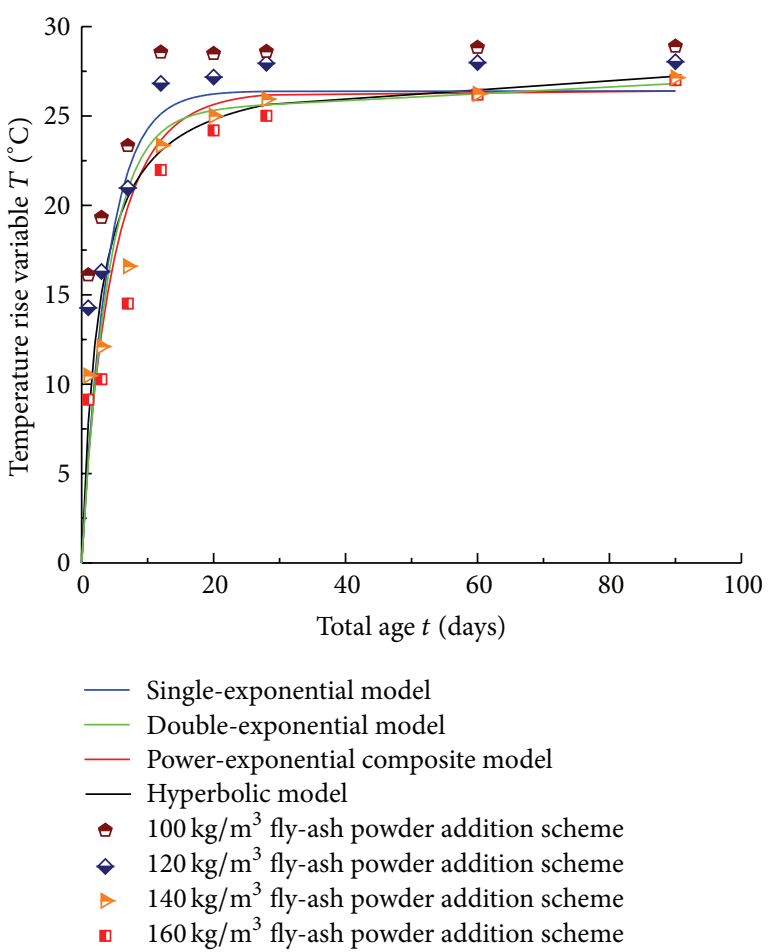

FIGURE 13: Comparisons of temperature rise tests' data and conventional models.

Fly-ash powder and silica fume in this paper were the targeted agents to be researched for their effects. Based on the standard constituents percentages, four fly-ash powder addition schemes $\left(100,120,140\right.$, and $\left.160 \mathrm{~kg} / \mathrm{m}^{3}\right)$ and four silica fume addition schemes $\left(12.5,17.5,22.5\right.$, and $\left.27.5 \mathrm{~kg} / \mathrm{m}^{3}\right)$ were considered, respectively. Then, we studied the sensitive feedback of stress and thermodynamic characteristics of Sino high strength hydraulic concrete.

6.1. Temperature Rise Procedure Sensitivity. We monitored the temperature rise procedures of the targeted concrete material with different fly-ash powder addition levels and the data were compared with the four conventional models in Figure 13. According to our study, the fly-ash powder is the indispensable constituent of Sino HSHC. Its application can effectively reduce the hydration heat discharge in the early stage of the concrete pouring procedure.

Figure 13 shows that the values computed by these models converge in the mature stage and the obvious discrepancy just lives in the early stage of hydration heat development. Meantime, the temperature rise procedures of Sino HSHC material show obvious discreteness from the conventional models' calculation. Hence, the updated hyperbolic model was chosen to express properly the effects of fly-ash powder addition levels:

$$
T=\frac{t}{\alpha t+\lambda}
$$




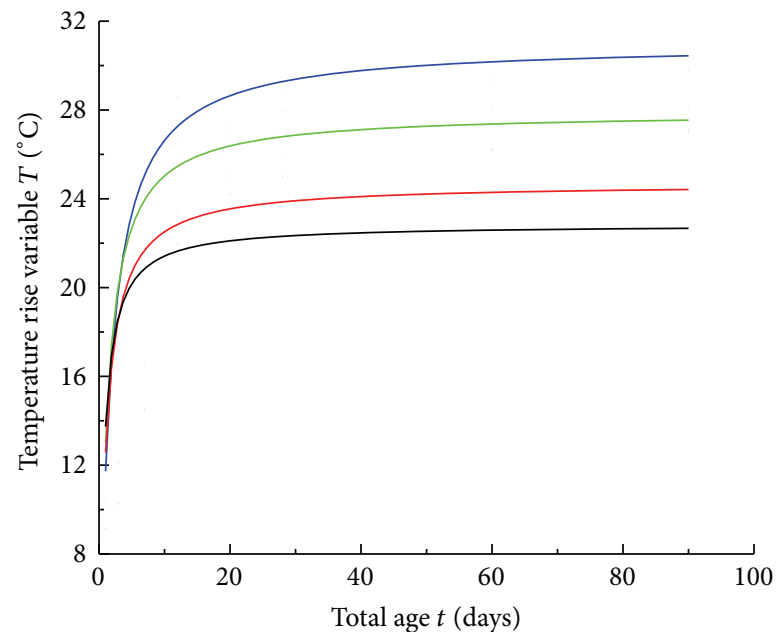

$100 \mathrm{~kg} / \mathrm{m}^{3} \mathrm{fly}$-ash powder addition scheme — $120 \mathrm{~kg} / \mathrm{m}^{3}$ fly-ash powder addition scheme

— $140 \mathrm{~kg} / \mathrm{m}^{3}$ fly-ash powder addition scheme

$160 \mathrm{~kg} / \mathrm{m}^{3}$ fly-ash powder addition scheme

FIgURE 14: Theoretical temperature rise procedures based on updated hyperbolic model.

where test parameters $\alpha$ and $\lambda$ are the functions of fly-ash powder addition level $x$ and can be computed by

$$
\begin{aligned}
& \alpha=f_{0}+f_{1} e^{x / f_{2},} \\
& \lambda=f_{3}+f_{4} x,
\end{aligned}
$$

where $f_{0}=0.01, f_{1}=0.00597, f_{2}=81.57837, f_{3}=0.0636$, and $f_{4}=-1.963$.

The theoretical temperature rise procedures based on (10) can be expressed by Figure 14 .

In (10), the value of $\alpha$ will rise with the increasement of fly-ash powder addition level $x$; on the contrary, the value of $\lambda$ will fall clearly (in Figure 15). Therefore, it is believed that the updated hyperbolic model can incorporate the thermodynamic effect of fly-ash powder addition level over the temperature rise procedures of Sino HSHC.

\subsection{Thermodynamic Creep and Stress Characteristics Sensitiv-} ities. Figure 16 shows the sensitive curves of creep development of the targeted materials with different ages ( 7 days and 28 days).

The persistent curing activities are also helpful for the reduction of creep value level. The longer curing age will facilitate the lower level of both recoverable and unrecoverable creep developments. The ribbon of creep development on the silica fume addition levels (Figure 16(b)) is narrower than that on fly-ash powder addition levels (Figure 16(a)). Therefore, the thermodynamic creep of Sino HSHC material is not sensitive to the addition level of silica fume. Under the standard constituents percentages, the cumulative gradient of thermodynamic creep at 7 days age is $0.07 \times 10^{-6} \mathrm{MPa}$ /day

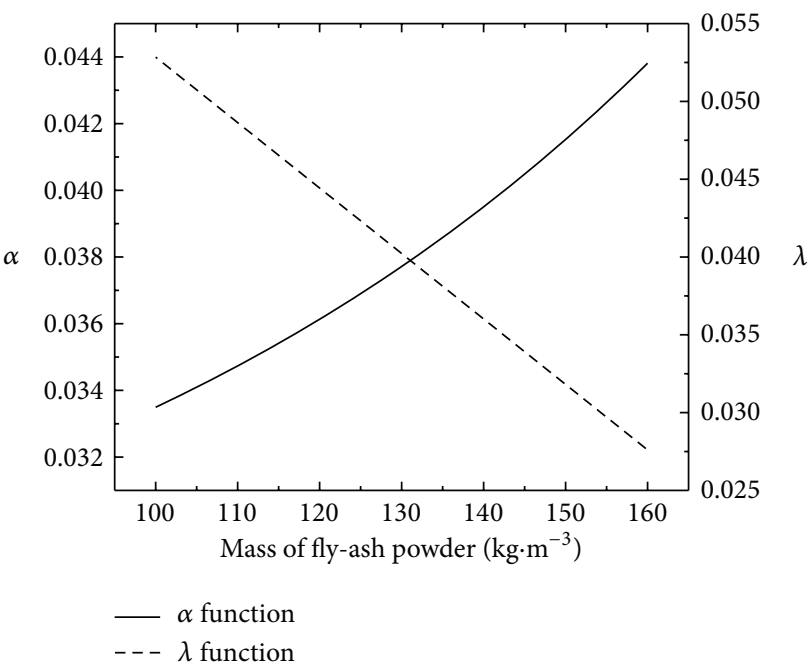

FIgURE 15: $\alpha$ and $\lambda$ functions on fly-ash powder addition levels.

that meets the requirements of the international concrete construction code [31]:

(a1) Fly-ash powder case under uniaxial compressive loading condition, sample's age: 28 days.

(a2) Silica fume case under uniaxial compressive loading condition, sample's age: 28 days.

(b1) Fly-ash powder case under biaxial compressive loading condition, for vertical axis, sample's age: 28 days.

(b2) Fly-ash powder case under biaxial compressive loading condition, for horizontal axis, sample's age: 28 days.

(b3) Silica fume case under biaxial compressive loading condition, for vertical axis, sample's age: 28 days.

(b4) Silica fume case under biaxial compressive loading condition, for horizontal axis, sample's age: 28 days.

Figure 17 shows the complete stress-strain constitutive curves under multiaxial compressive loading tests. The mechanical behaviors of the targeted concrete material comply with nonlinear constitutive characteristic under multiaxial compressive loading conditions. Furthermore, the nonlinear constitutive characteristics of Sino HSHC show highly sensitive feedback to the addition levels of the targeted agents, that is, fly-ash powder and silica fume.

Under the standard constituents percentages condition, the values of uniaxial ultimate strength $\left(\sigma_{f}\right)$ and vertical axial ultimate strength $\left(\sigma_{1_{f}}\right)$ keep steadily in the range of 55-65 MPa. However, the horizontal axial ultimate strength $\left(\sigma_{2_{f}}\right)$ fluctuates clearly with the diverse replacement of the targeted agents: the application of fly-ash powder will degrade the horizontal axial ultimate strength down to $35 \mathrm{MPa}$; the application of silica fume will promote the horizontal axial ultimate strength up to $70 \mathrm{MPa}$. The causes for this phenomenon include the active material with higher strength 


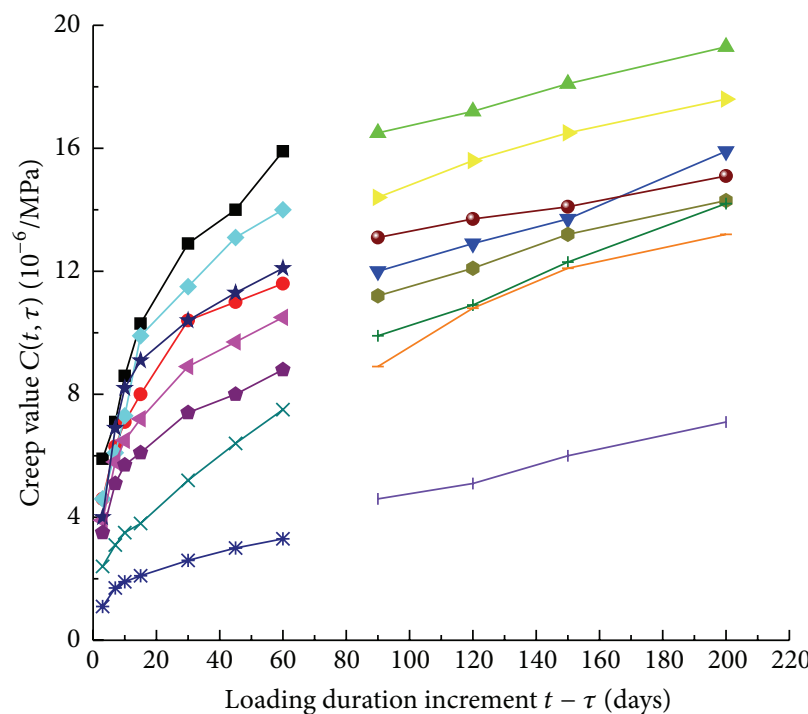

- Recoverable creep for 7 days age $\quad 100 \mathrm{~kg} / \mathrm{m}^{3}$

$\rightarrow$ Recoverable creep for 28 days age fly-ash powder

- Unrecoverable creep for 7 days age addition scheme

$\neg$ Unrecoverable creep for 28 days age

$\because-$ Recoverable creep for 7 days age $120 \mathrm{~kg} / \mathrm{m}^{3}$

- Recoverable creep for 28 days age fly-ash powder

$\rightarrow$ Unrecoverable creep for 7 days age addition scheme

$\rightarrow$ Unrecoverable creep for 28 days age

* Recoverable creep for 7 days age $140 \mathrm{~kg} / \mathrm{m}^{3}$

$\rightarrow-$ Recoverable creep for 28 days age fly-ash powder

$\rightarrow$ Unrecoverable creep for 7 days age addition scheme

$\leftarrow$ Unrecoverable creep for 28 days age

$*$ Recoverable creep for 7 days age $\quad 160 \mathrm{~kg} / \mathrm{m}^{3}$

* Recoverable creep for 28 days age fly-ash powder

- Unrecoverable creep for 7 days age addition scheme

— Unrecoverable creep for 28 days age

(a) Fly-ash powder case

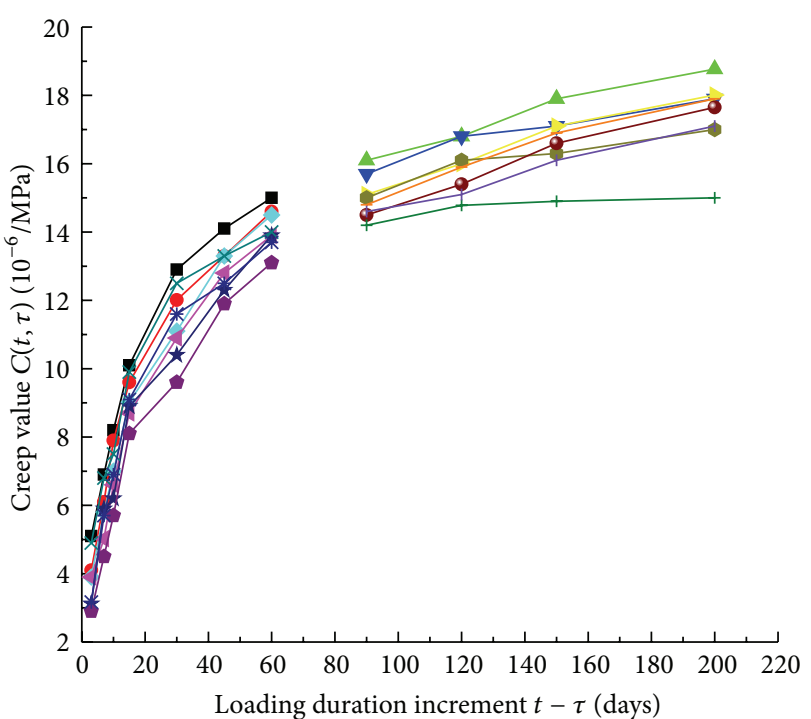

- Recoverable creep for 7 days age $12.5 \mathrm{~kg} / \mathrm{m}^{3}$

$\rightarrow$ Recoverable creep for 28 days age silica fume

- Unrecoverable creep for 7 days age addition scheme

$\rightarrow$ Unrecoverable creep for 28 days age

$\longrightarrow$ Recoverable creep for 7 days age $17.5 \mathrm{~kg} / \mathrm{m}^{3}$

$\longleftarrow$ Recoverable creep for 28 days age $\}$ silica fume

$\rightarrow$ Unrecoverable creep for 7 days age $\left\{\begin{array}{l}\text { addition scheme } \\ \text { andica }\end{array}\right.$

- Unrecoverable creep for 28 days age

* Recoverable creep for 7 days age $22.5 \mathrm{~kg} / \mathrm{m}^{3}$

$\rightarrow$ Recoverable creep for 28 days age $\}$ silica fume

$\rightarrow$ Unrecoverable creep for 7 days age addition scheme

- Unrecoverable creep for 28 days age

$\rightarrow$ Recoverable creep for 7 days age $\quad 27.5 \mathrm{~kg} / \mathrm{m}^{3}$

* Recoverable creep for 28 days age $\} \begin{aligned} & 27.5 \mathrm{~kg} / \mathrm{m} \\ & \text { silica fume }\end{aligned}$

- Unrecoverable creep for 7 days age $\int \begin{aligned} & \text { addition scheme } \\ & \text { and }\end{aligned}$

- Unrecoverable creep for 28 days age

(b) Silica fume case

FIGURE 16: Sensitive curves of creep development.

than $\mathrm{Ca}(\mathrm{OH})_{2}$ crystal, namely, $2 \mathrm{CaO} \cdot \mathrm{SiO}_{2} \cdot \mathrm{H}_{2} \mathrm{O}$ generated from the silica fume stuffs densely and continually the interfaces of the cements hydrates and the aggregates particles by which the concrete material gets super homogeneity and can bear safely the complex loading case; higher replacement level of fly-ash powder fabricates larger voids between the cements hydrates and the fly-ash particles that will devour more hydrates whose propagation may consume much time and cause particularly higher heterogeneity and lower strength at the early stage.

The degenerative level of ultimate strength rises sharp when the silica fume addition level decreases under uniaxial compressive loading condition: under the case of $27.5 \mathrm{~kg} / \mathrm{m}^{3}$, the uniaxial ultimate strength will rocket up to $80 \mathrm{MPa}$; however, under the case of $12.5 \mathrm{~kg} / \mathrm{m}^{3}$, it will reduce down to $45 \mathrm{MPa}$.

The vertical axial ultimate strength of biaxial compressive loading cases is sensitive to the fly-ash powder addition levels.
Its value under the case of $160 \mathrm{~kg} / \mathrm{m}^{3}$ is lower than that under the case of $100 \mathrm{~kg} / \mathrm{m}^{3}$ by $20 \mathrm{MPa}$.

The mechanical strain under multiaxial also shows the obvious sensitivities to the addition levels of fly-ash powder and silica fume.

As a whole, the peak strain levels with the silica fume application are higher than that with the fly-ash powder application (Figure 18). The phenomenon means that the application of silica fume helps Sino HSHC develop the continuous deformation with higher level before it is destroyed seriously. The super quality is realized by its homogeneity due to the active material generation. Under the biaxial compressive loading condition, the value of $\varepsilon_{2_{f}}$ of the targeted concrete attains above 0.36 (Figure 18(b4)). The value of $\varepsilon_{2_{f}}$, even under the uniaxial compressive loading condition that is a more disadvantageous stress state, can reach up to 0.002 (Figure 18(a2)). Therefore, Sino HSHC material with the silica fume application can undergo the rigorous stress states. 


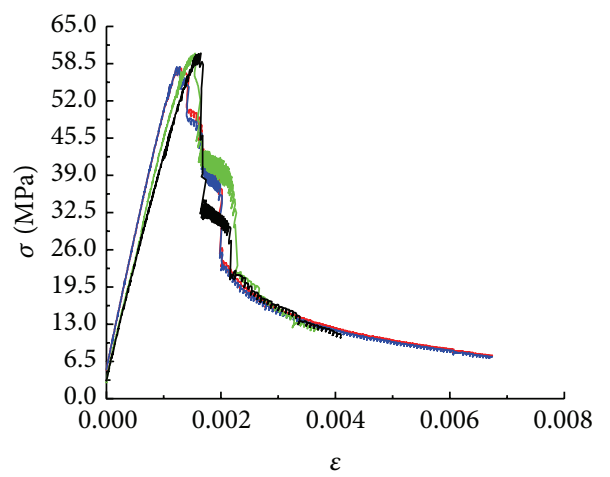

$100 \mathrm{~kg} / \mathrm{m}^{3} \mathrm{fly}$-ash powder addition scheme $120 \mathrm{~kg} / \mathrm{m}^{3}$ fly-ash powder addition scheme - $140 \mathrm{~kg} / \mathrm{m}^{3}$ fly-ash powder addition scheme - $160 \mathrm{~kg} / \mathrm{m}^{3}$ fly-ash powder addition scheme

(a1)

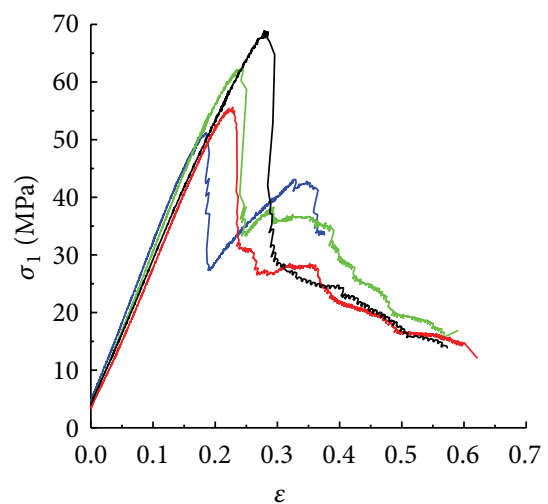

$100 \mathrm{~kg} / \mathrm{m}^{3}$ fly-ash powder addition scheme $120 \mathrm{~kg} / \mathrm{m}^{3}$ fly-ash powder addition scheme $140 \mathrm{~kg} / \mathrm{m}^{3}$ fly-ash powder addition scheme $160 \mathrm{~kg} / \mathrm{m}^{3}$ fly-ash powder addition scheme

(b1)

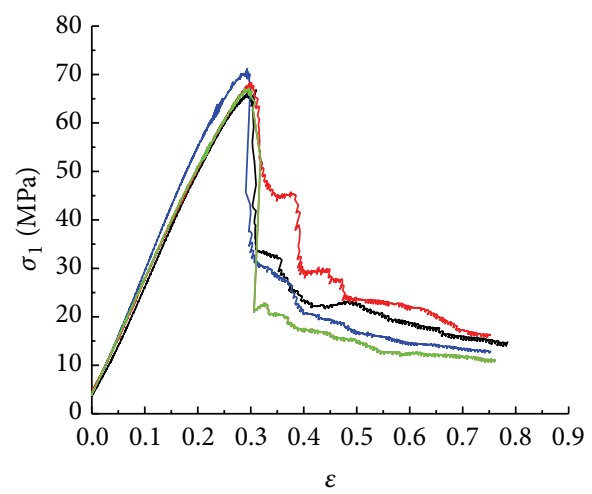

- $12.5 \mathrm{~kg} / \mathrm{m}^{3}$ silica fume addition scheme $17.5 \mathrm{~kg} / \mathrm{m}^{3}$ silica fume addition scheme $22.5 \mathrm{~kg} / \mathrm{m}^{3}$ silica fume addition scheme - $27.5 \mathrm{~kg} / \mathrm{m}^{3}$ silica fume addition scheme

(b3)

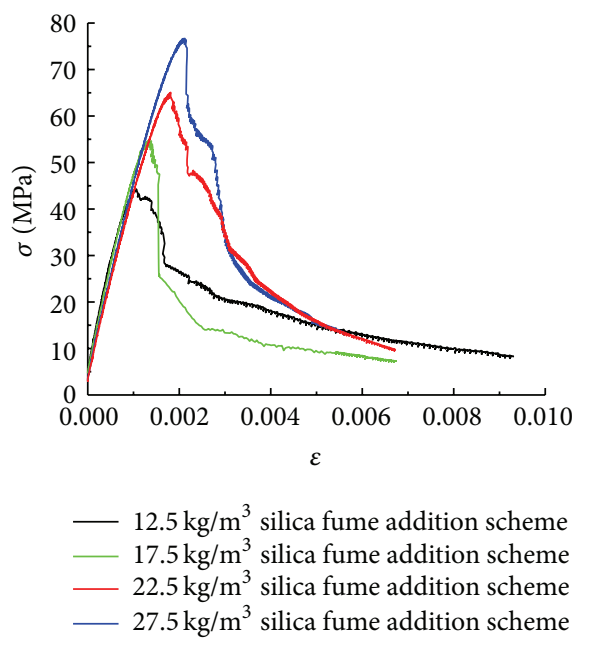

(a2)

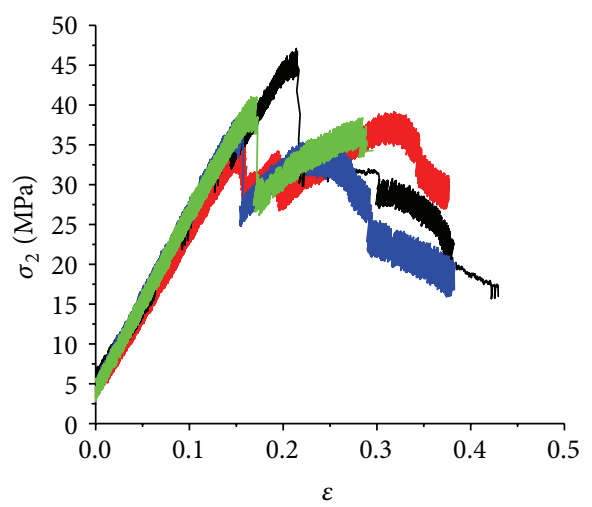

$100 \mathrm{~kg} / \mathrm{m}^{3}$ fly-ash powder addition scheme $120 \mathrm{~kg} / \mathrm{m}^{3}$ fly-ash powder addition scheme

- $140 \mathrm{~kg} / \mathrm{m}^{3}$ fly-ash powder addition scheme

$160 \mathrm{~kg} / \mathrm{m}^{3}$ fly-ash powder addition scheme

(b2)

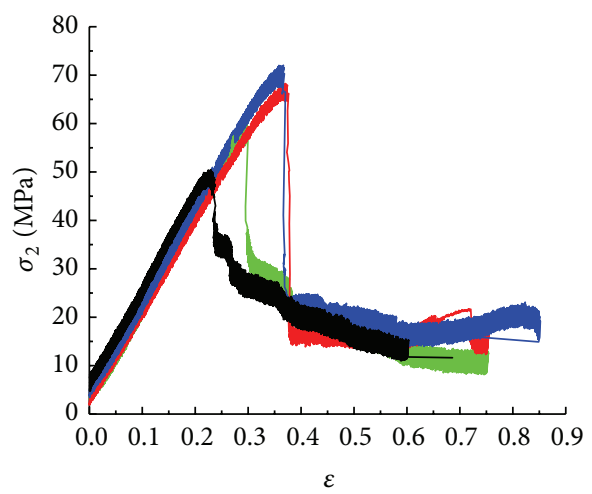

- $12.5 \mathrm{~kg} / \mathrm{m}^{3}$ silica fume addition scheme $17.5 \mathrm{~kg} / \mathrm{m}^{3}$ silica fume addition scheme

$22.5 \mathrm{~kg} / \mathrm{m}^{3}$ silica fume addition scheme

— $27.5 \mathrm{~kg} / \mathrm{m}^{3}$ silica fume addition scheme

(b4)

FIGURE 17: Complete stress-strain constitutive curves. (a1) Fly-ash powder case under uniaxial compressive loading condition, sample's age: 28 days. (a2) Silica fume case under uniaxial compressive loading condition, sample's age: 28 days. (b1) Fly-ash powder case under biaxial compressive loading condition, for vertical axis, sample's age: 28 days. (b2) Fly-ash powder case under biaxial compressive loading condition, for horizontal axis, sample's age: 28 days. (b3) Silica fume case under biaxial compressive loading condition, for vertical axis, sample's age: 28 days. (b4) Silica fume case under biaxial compressive loading condition, for horizontal axis, sample’s age: 28 days. 


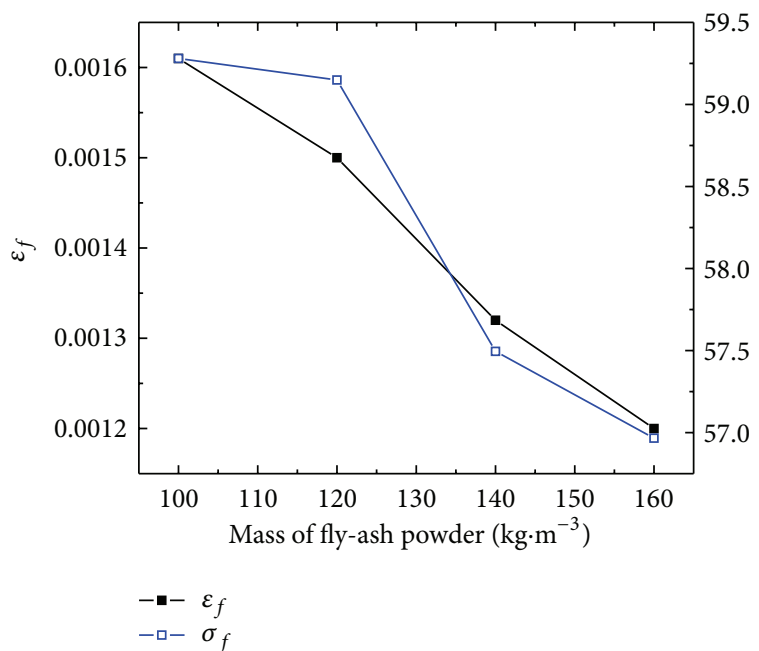

(a1)

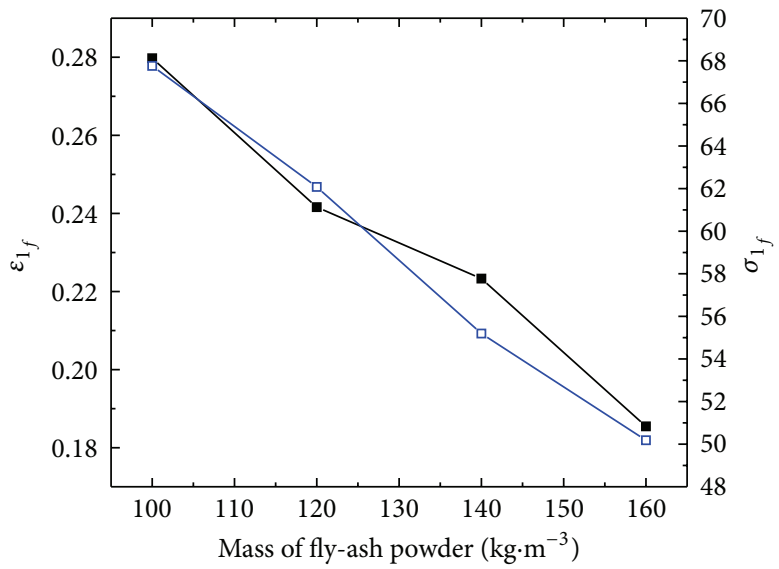

$$
\begin{array}{ll}
-\square & \varepsilon_{1_{f}} \\
-\square- & \sigma_{1_{f}}
\end{array}
$$

(b1)

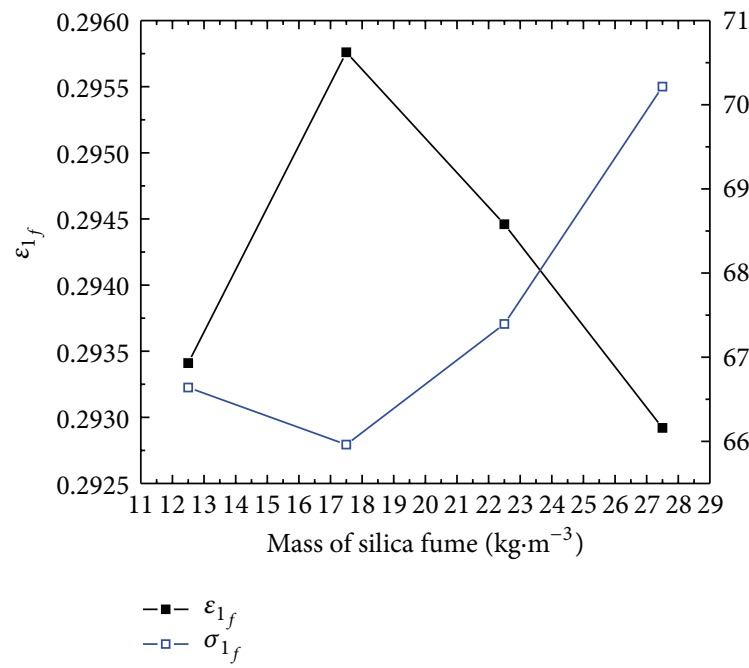

(b3)

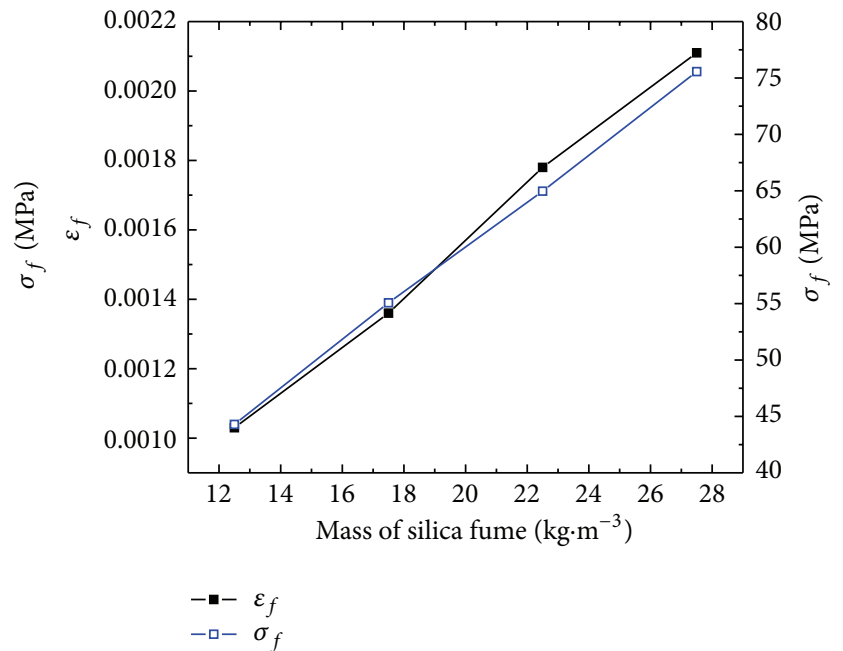

(a2)

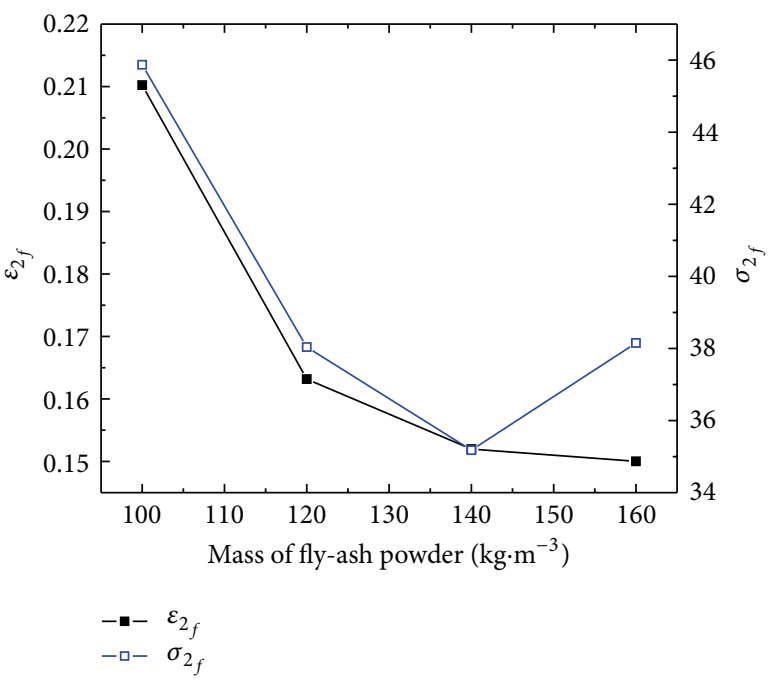

(b2)

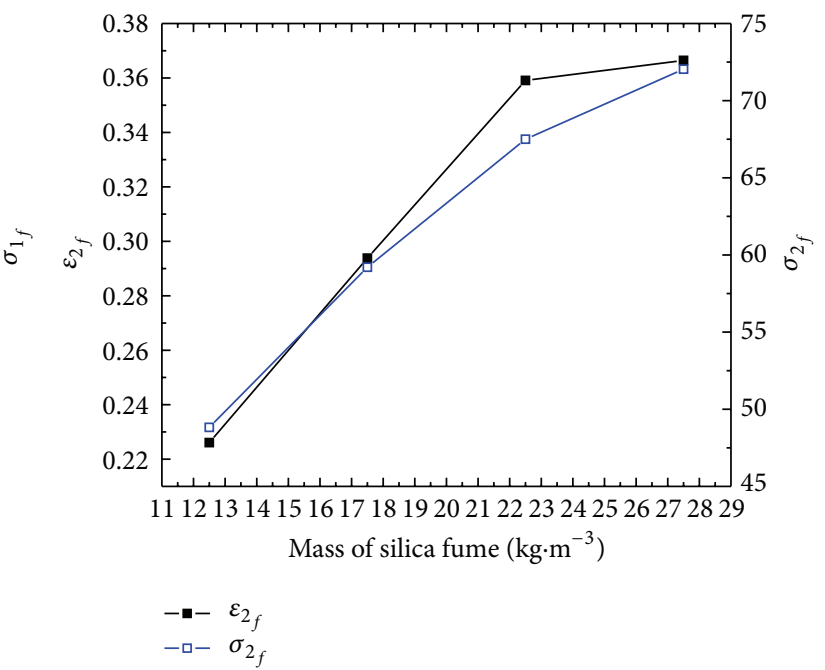

(b4)

Figure 18: Peak strain and ultimate strength. (a1) Fly-ash powder case under uniaxial compressive loading condition, sample's age: 28 days. (a2) Silica fume case under uniaxial compressive loading condition, sample's age: 28 days. (b1) Fly-ash powder case under biaxial compressive loading condition, for vertical axis, sample's age: 28 days. (b2) Fly-ash powder case under biaxial compressive loading condition, for horizontal axis, sample's age: 28 days. (b3) Silica fume case under biaxial compressive loading condition, for vertical axis, sample's age: 28 days. (b4) Silica fume case under biaxial compressive loading condition, for horizontal axis, sample's age: 28 days. 


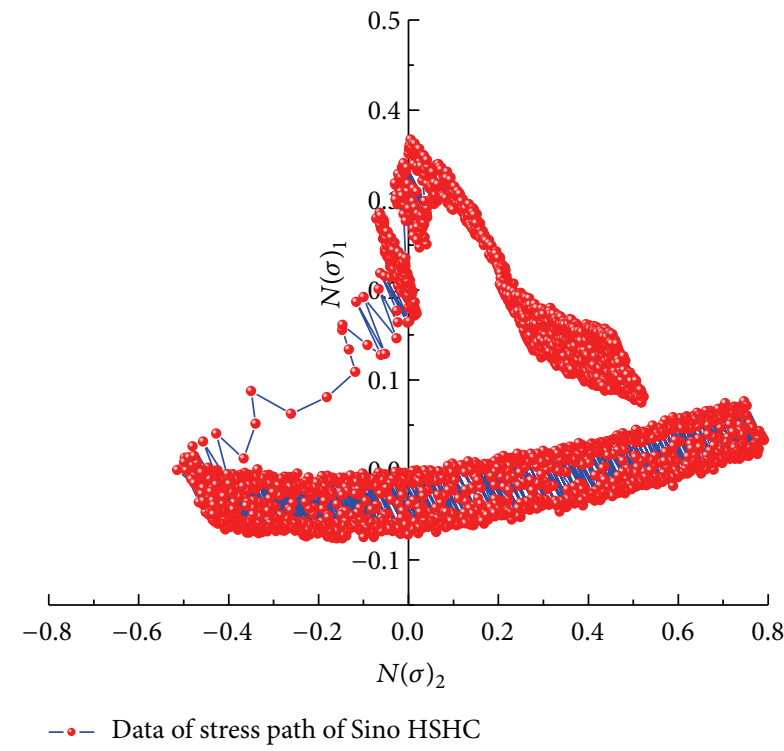

(a) Stress path under optimal constituents' scheme

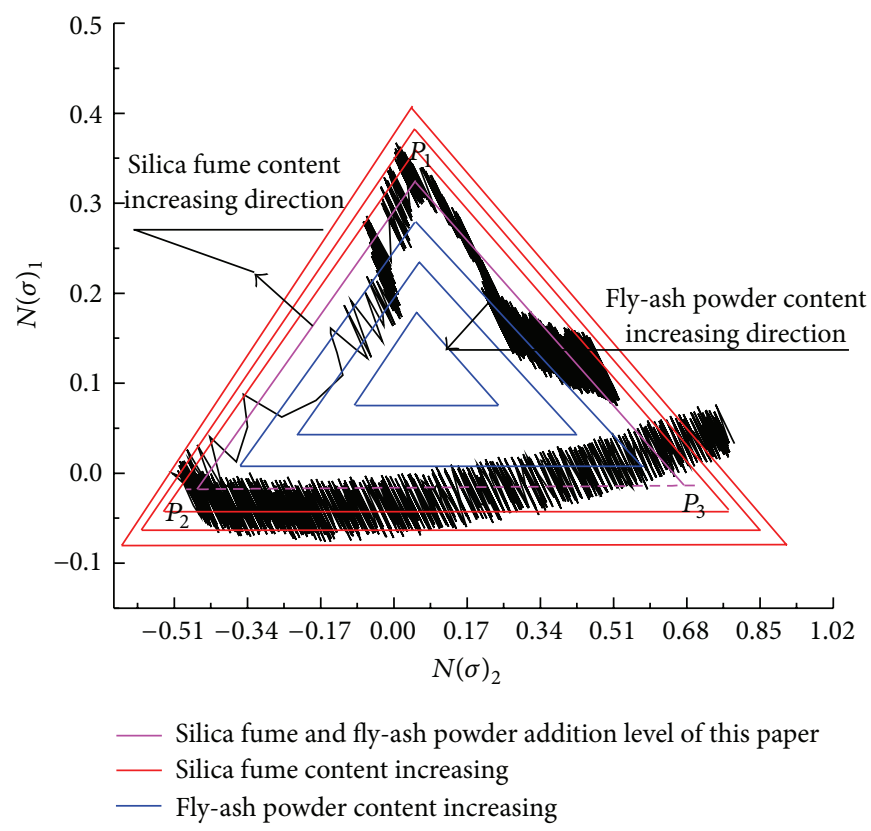

(b) Stress paths comparison

FIgURE 19: Concrete stress paths characteristics sensitivities.

The stress path characteristics are the inspiring tools for understanding the quality of Sino HSHC material under complex stress states. The cognition in its stress path development helps scientists and engineers apply properly the HSHC material in complicated circumstances (Figure 19).

The normalized stress space and its coordinate system can be expressed as $\sigma_{2} / \sigma_{2_{f}} \sim \sigma_{1} / \sigma_{1_{f}}$. The further coordinate transformation can be expressed by (12). The updated stress path can be showed under the transformed coordinate system $N(\sigma)_{2} \sim N(\sigma)_{1}$ as in Figure 19:

$$
\begin{aligned}
& N^{\prime}(\sigma)_{2}=\frac{\sigma_{2}}{\sigma_{2_{f}}} \cos \alpha_{0}+\frac{\sigma_{1}}{\sigma_{1_{f}}} \sin \alpha_{0}, \\
& N^{\prime}(\sigma)_{1}=\frac{\sigma_{1}}{\sigma_{1_{f}}} \cos \alpha_{0}-\frac{\sigma_{2}}{\sigma_{2_{f}}} \sin \alpha_{0} ; \\
& N(\sigma)_{2}=N^{\prime}(\sigma)_{2}+\delta, \\
& N(\sigma)_{1}=N^{\prime}(\sigma)_{1},
\end{aligned}
$$

where $N^{\prime}(\sigma)_{2}$ and $N^{\prime}(\sigma)_{1}$ are the intermediate coordinate system with a rotation transformation from $\sigma_{2} / \sigma_{2_{f}} \sim \sigma_{1} / \sigma_{1_{f}}$, $\sigma_{2} / f_{\mathcal{C}_{2}} \sim \sigma_{1} / f_{\mathcal{c}_{1}} ; \alpha_{0}=135^{\circ}$ is the rotation angle for normal stress space; $N(\sigma)_{2}$ and $N(\sigma)_{1}$ are the eventual coordinate system with a translation transformation from $\mathrm{N}^{\prime}(\sigma)_{2}$ and $N^{\prime}(\sigma)_{1} ; \delta=0.90$ is the translation distance from the intermediate coordinate system $N^{\prime}(\sigma)_{2}$ and $N^{\prime}(\sigma)_{1}$ to the eventual coordinate system $N(\sigma)_{2}$ and $N(\sigma)_{1} ; N^{\prime}(\sigma)_{1}, N^{\prime}(\sigma)_{2}, N(\sigma)_{1}$, and $N(\sigma)_{2}$ are the relative values on stress, namely, nondimensional parameters calculated by (12).

With the same internal addition method, the sensitivity of stress path characteristics of the HSHC material was studied on fly-ash powder and silica fume addition. The results show that the higher the content of silica fume is, the longer the total length of the stress path is; the higher the content of fly-ash is, the shorter the total length of the stress path is. Therefore, the two main agents, that is, fly-ash powder and silica fume, play different roles in the multimechanicalphysical characteristics of the high strength hydraulic concrete material. The longer stress paths can form larger areas in stress space and the larger stress space areas will offer higher strength and resistance. Furthermore, the larger stress space areas can generate super durability under the complicate stress states. The results in Figure 19 consist with that in Figure 18.

Although the application of fly-ash powder will weaken the strength of the concrete material, its proper addition level can restrain effectively the thermodynamic creep development (Figures 16 and 20).

The compressive yield strength of the concrete material will decline with the increase of fly-ash powder addition level. By contrast, its creep values will run lower, too. The compressive yield strength of the concrete material will grow with the increase of silica fume addition level. However, the increasing effect tends to converge. Meanwhile, its creep values will reach minimum $\left(17.65 \times 10^{-6} / \mathrm{MPa}, 7\right.$ days age; $15 \times 10^{-6} / \mathrm{MPa}, 28$ days age) with the increase of silica fume addition level (Figure 20). 


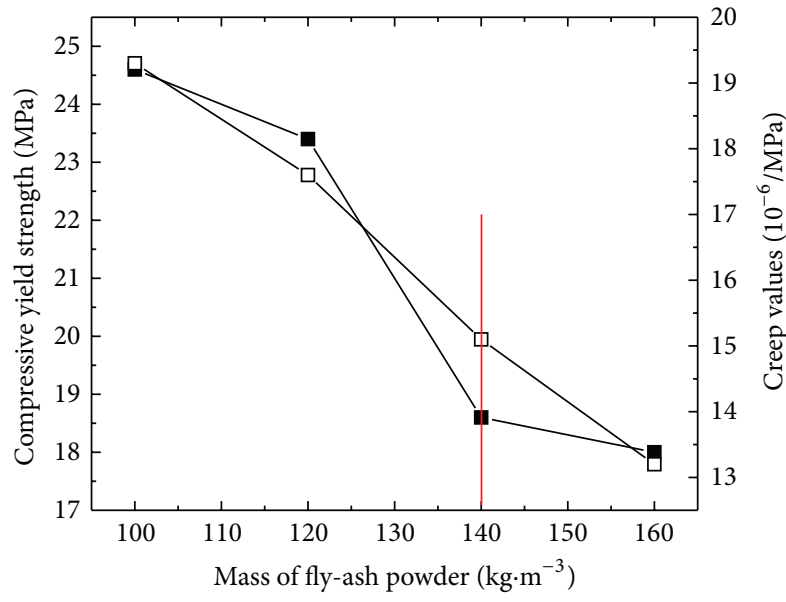

-- Compressive yield strength with 7 days curing age - - Creep values with 7 days curing age

(a) Fly-ash powder case, sample's age: 7 days

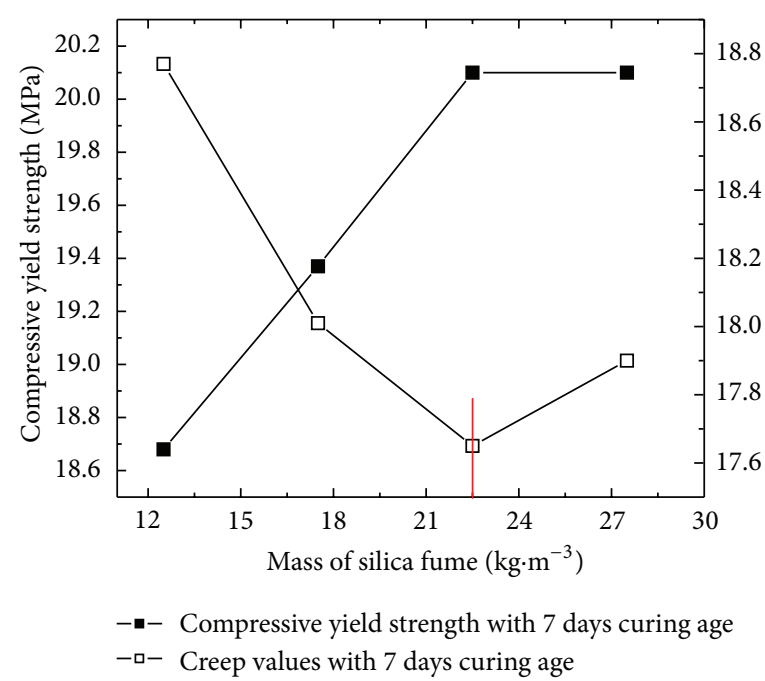

(c) Silica fume case, sample's age: 7 days

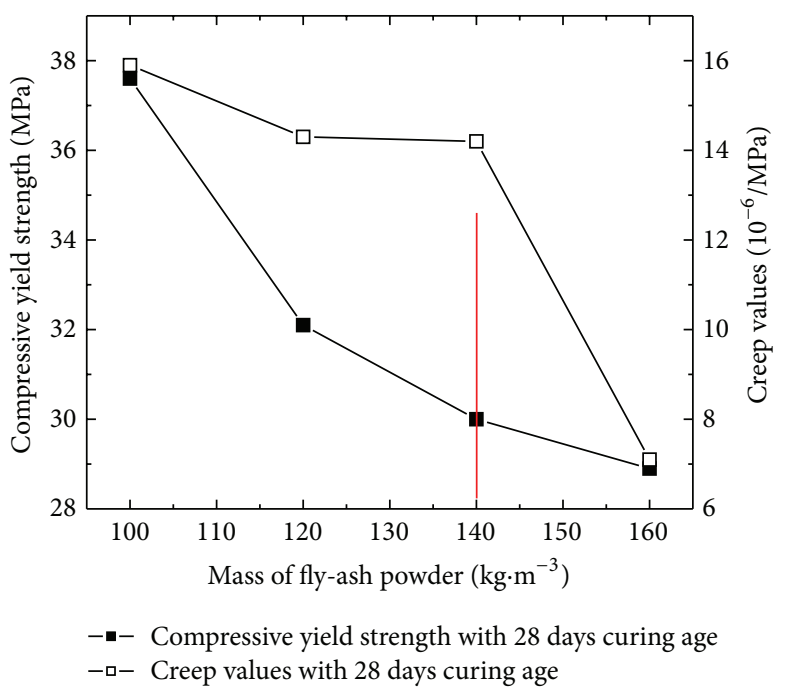

(b) Fly-ash powder case, sample's age: 28 days

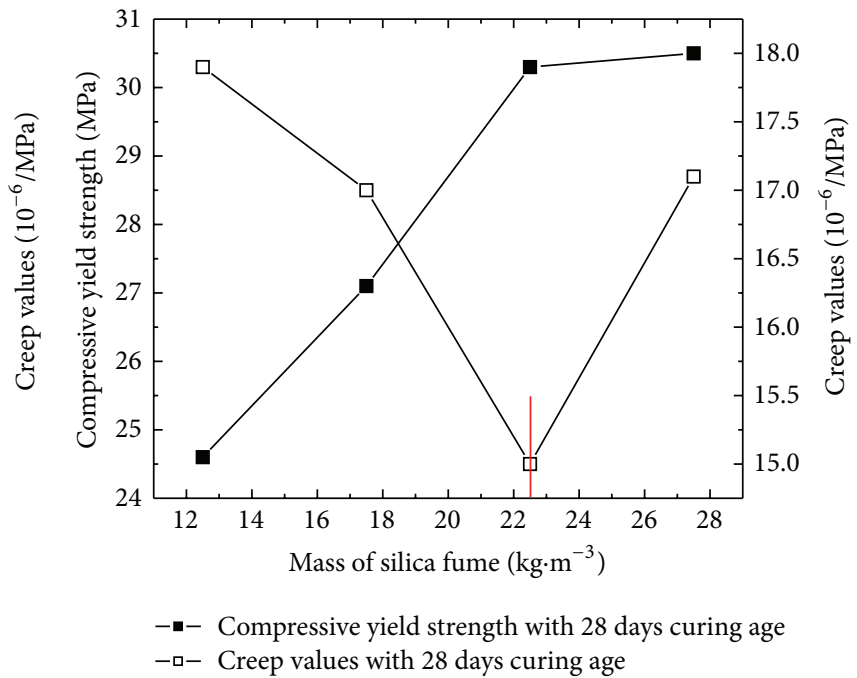

(d) Silica fume case, sample's age: 28 days

FIGURE 20: Compressive yield strength and thermodynamic characteristics sensitivities.

Due to the double application of fly-ash powder and silica fume, there must be somewhat replacement for the cement amount in Sino HSHC material. However, the replacement influence can be attenuated effectively with the curing age continuing (Figures 20(b) and 20(d)).

Moreover, the compressive yield strengths of Sino HSHC show explicit sensitivities to the curing ages. Under the case of $160 \mathrm{~kg} / \mathrm{m}^{3}$ for fly-ash powder addition, the value of compressive yield strength can reach only $17 \mathrm{MPa}$ at the age of 7 days. However, the value can grow up to $29 \mathrm{MPa}$ at the age of 28 days. The cumulative gradient is $0.52 \mathrm{MPa}$ /day. By contrast, under the case of $27.5 \mathrm{~kg} / \mathrm{m}^{3}$ for silica fume addition, the cumulative gradient of compressive yield strength is $0.47 \mathrm{MPa} /$ day.

\section{Conclusions}

Sino hydraulic construction shows both unbeatable ambition and unsurpassable complexity. This paper tried to introduce comprehensively the key aspects of Sino HSHC material. The following conclusions are drawn:

(1) Four fly-ash powder addition schemes and four silica fume addition schemes were designed. Based on them, the concrete material's thermodynamic creep sensitivities to the targeted agents' addition levels were studied: the completely thermodynamic creep developments at different ages were tested and compared; the creep developments show obvious sensitivities to the fly-ash powder addition levels; in order to 
qualify the creep development, one new thermodynamic creep model was established and its simulation results show higher accuracy than the old one.

(2) The temperature rise procedures of the targeted concrete were monitored on the spot; the measured data were compared with the conventional temperature rise model and the results show explicit discreteness from each other; the updated hyperbolic model was established and its parameters' functions on the flyash powder addition levels were offered.

(3) Based on the multiaxial loading tests, the stress-strain constitutive curves of the targeted concrete were completed; the sensitivity of the stress path characteristics was studied; the results prove that the proper addition of silica fume in the targeted concrete can facilitate the strength development. Particularly, the strength sensitivities to the curing ages were studied. The application of fly-ash powder can promote the strength development at the early stage.

\section{Competing Interests}

The author declares that there are no competing interests regarding the publication of this paper.

\section{Acknowledgments}

This work was supported by the National Natural Science Foundation of China (Grant no. 51109118) and Zhejiang Provincial Natural Science Foundation of China (Grant no. LY14E090001).

\section{References}

[1] B.-J. Fu, B.-F. Wu, Y.-H. Lü et al., "Three Gorges Project: efforts and challenges for the environment," Progress in Physical Geography, vol. 34, no. 6, pp. 741-754, 2010.

[2] C. N. Liu, C. R. Ahn, X. H. An, and S. Lee, "Life-cycle assessment of concrete dam construction: comparison of environmental impact of rock-filled and conventional concrete," Journal of Construction Engineering and Management, vol. 139, no. 12, pp. 1-11, 2013.

[3] J. J. Zhou, J. L. Pan, C. K. Y. Leung, and Z. J. Li, "Experimental study on mechanical behavior of high performance concrete under multi-axial compressive stress," Science ChinaTechnological Sciences, vol. 57, no. 12, pp. 2514-2522, 2014.

[4] L. L. Shi, L. C. Wang, Y. P. Song, and L. Shen, "Dynamic multiaxial strength and failure criterion of dam concrete," Construction and Building Materials, vol. 66, pp. 181-191, 2014.

[5] J. S. Jia, Y. L. Yuan, C. Y. Zheng, and Z. L. Ma, "Dam construction in China: statistics, progresses and concerned issues," Water Power, vol. 36, pp. 6-10, 2010.

[6] C. Miao, A. G. L. Borthwick, H. Liu, and J. Liu, "China’s policy on dams at the crossroads: removal or further construction?" Water, vol. 7, no. 5, pp. 2349-2357, 2015.

[7] M. Chabannes, E. Garcia-Diaz, L. Clerc, and J. C. Benezet, "Effect of curing conditions and $\mathrm{Ca}(\mathrm{OH})_{2}$-treated aggregates on mechanical properties of rice husk and hemp concretes using a lime-based binder," Construction and Building Materials, vol. 102, part 1, pp. 821-833, 2016.
[8] M. Amareanu and L. Melita, "A comparative research study concerning the cements composition influence on the durability and physical-mechanical properties of the concretes," European Journal of Environmental and Civil Engineering, vol. 20, no. 2, pp. 282-300, 2015.

[9] H. S. Lee and S. J. Kwon, "Effects of magnetite aggregate and steel powder on thermal conductivity and porosity in concrete for nuclear power plant," Advances in Materials Science and Engineering, vol. 2016, Article ID 9526251, 8 pages, 2016.

[10] J. Rex and B. Kameshwari, "Studies on pumice lightweight aggregate concrete with quarry dust using mathematical modeling aid of ACO techniques," Advances in Materials Science and Engineering, vol. 2016, Article ID 9583757, 12 pages, 2016.

[11] Y. Peng, H. Wu, and Y. Zhuge, "Strength and drift capacity of squat recycled concrete shear walls under cyclic loading," Engineering Structures, vol. 100, pp. 356-368, 2015.

[12] X. L. Ge, C. R. Lu, and G. X. Mei, "Mechanical and frost resistance properties of high air content hydraulic concrete," Materials Research Innovations, vol. 19, supplement 5, pp. 510-513, 2015.

[13] ASTM International, "Standard test method for Portlandcement content of hardened hydraulic-cement concrete," Tech. Rep. ASTM C1084-10, ASTM International, West Conshohocken, Pa, USA, 2010.

[14] ACI Committee, "Building code requirements for structural concrete and commentary," ACI 318-14, American Concrete Institute, 2014

[15] S. H. Jung and S.-J. Kwon, "Engineering properties of cement mortar with pond ash in South Korea as construction materials: from waste to concrete," Central European Journal of Engineering, vol. 3, no. 3, pp. 522-533, 2013.

[16] X.-Y. Wang, "Evaluation of compressive strength of hardening silica fume blended concrete," Journal of Materials Science, vol. 48, no. 17, pp. 5953-5961, 2013.

[17] R. Ilangovana, N. Mahendrana, and K. Nagamanib, "Strength and durability properties of concrete containing quarry rock dust as fine aggregate," Journal of Engineering and Applied Sciences, vol. 3, no. 5, pp. 20-26, 2008.

[18] ACI Committee, "Load tests of concrete structures: methods, magnitude, protocols \& acceptance criteria," ACI 437.1R-07, American Concrete Institute, 2007.

[19] ACI Committee, "High-strength concrete in seismic regions," ACI SP-176, American Concrete Institute, 1998.

[20] ASTM, "Standard practice for examination and sampling of hardened concrete in constructions," ASTM C823/C823M-12, ASTM International, 2012.

[21] A. Ghali, R. Favre, and M. Elbadry, Concrete Structures: Stresses and Deformations, Chapmal and Hall, 1986.

[22] A. Lanciani, P. Morabito, P. Rossi et al., "Measurements of the thermophysical properties of structural materials in laboratory and in situ: methods and instrumentation," High Temperatures-High Pressures, vol. 21, no. 4, pp. 391-400, 1989.

[23] M. P. Manahan, "Thermal expansion and conductivity of magnetite flakes taken from the Oconee- 2 steam generator," Journal of Materials Science, vol. 25, no. 8, pp. 3424-3428, 1990.

[24] B. F. Zhu, "Computation of thermal stresses in mass concrete with consideration of creep effect," in Proceedings of the 15th International Congress on Large Dams, vol. 2, pp. 529-546, Lausanne, Switzerland, 1985. 
[25] G. Habert, D. Arribe, T. Dehove, L. Espinasse, and R. L. Roy, "Reducing environmental impact by increasing the strength of concrete: quantification of the improvement to concrete bridges," Journal of Cleaner Production, vol. 35, pp. 250-262, 2012.

[26] S. Anjan kumar and A. Veeraragavan, "Dynamic mechanical characterization of asphalt concrete mixes with modified asphalt binders," Materials Science and Engineering A, vol. 528, no. 21, pp. 6445-6454, 2011.

[27] RILEM and Final Recommendations of TC 162-TDF, "Test and design methods for steel fibre reinforced concrete, $\sigma-\varepsilon$ design method," Materials and Structures, vol. 36, pp. 560-565, 2003.

[28] ASTM, "Standard test method for density, relative density (specific gravity) and absorption of coarse aggregate," ASTM C12712, ASTM International, 2012.

[29] ASTM, "Standard test method for resistance to degradation of large size coarse aggregate by abrasion and impact in the LosAngeles machine," ASTM C535:12, 2012.

[30] ASTM International, "Standard test method for Sieve analysis of fine and coarse aggregate," Tech. Rep. ASTM C136-06, ASTM International, West Conshohocken, Pa, USA, 2006.

[31] ASTM, "Standard practice for making and curing concrete test specimens in the laboratory," ASTM C192/C192M-16, ASTM International, 2016. 

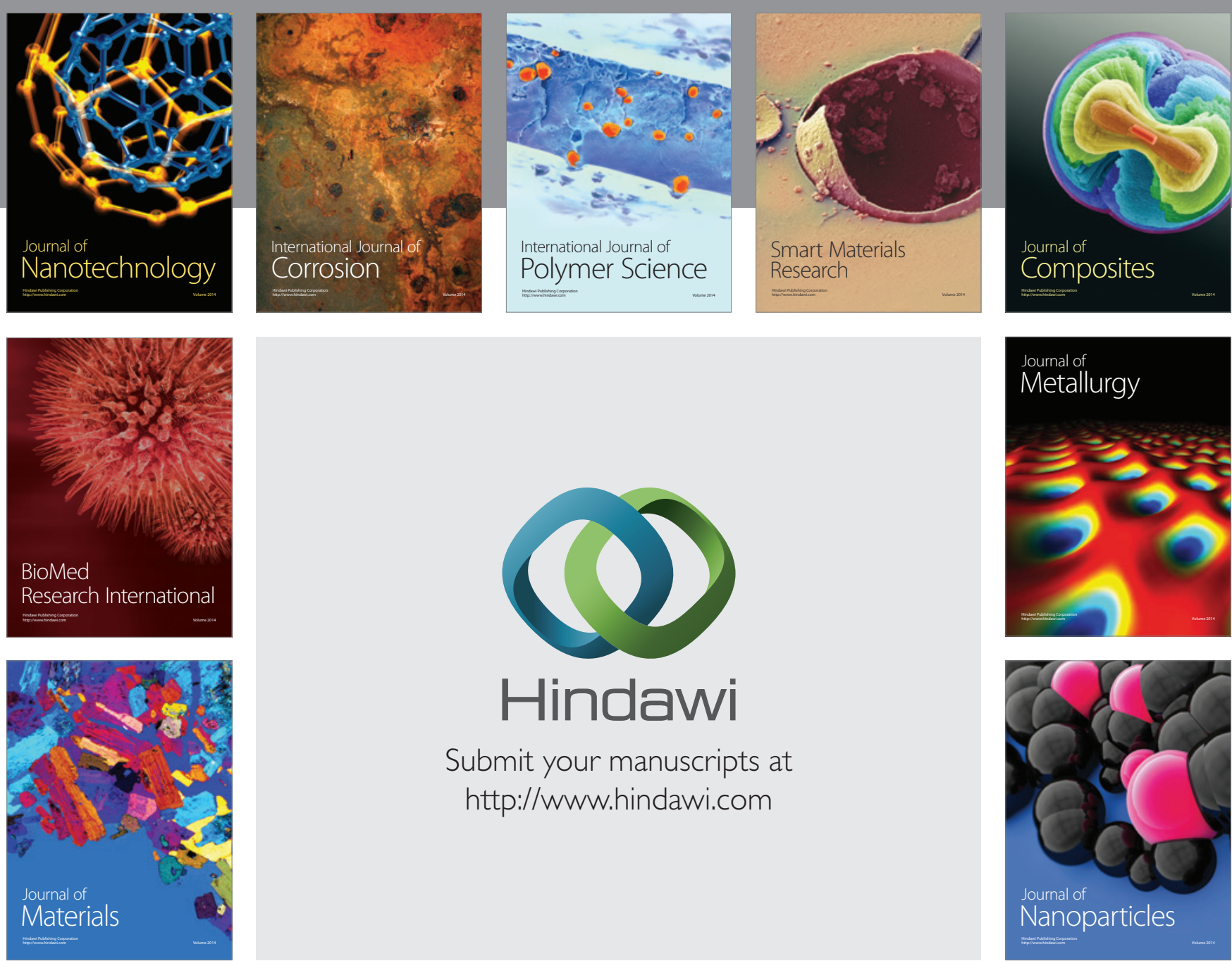

\section{Hindawi}

Submit your manuscripts at

http://www.hindawi.com

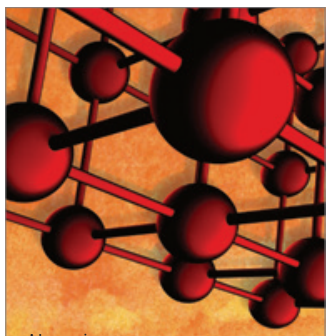

Materials Science and Engineering
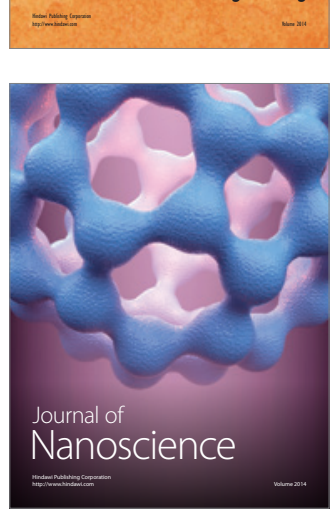
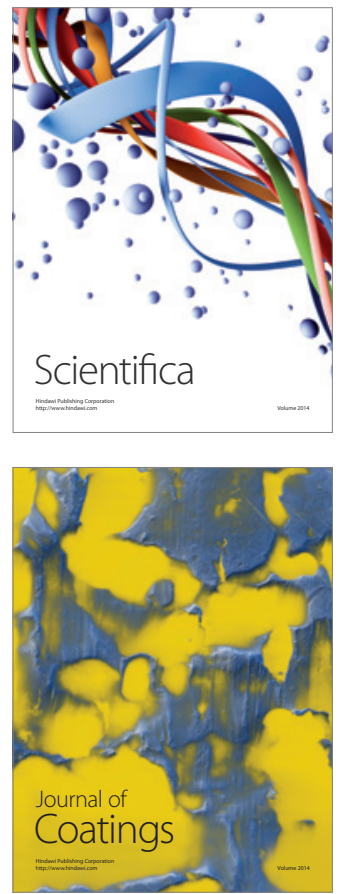
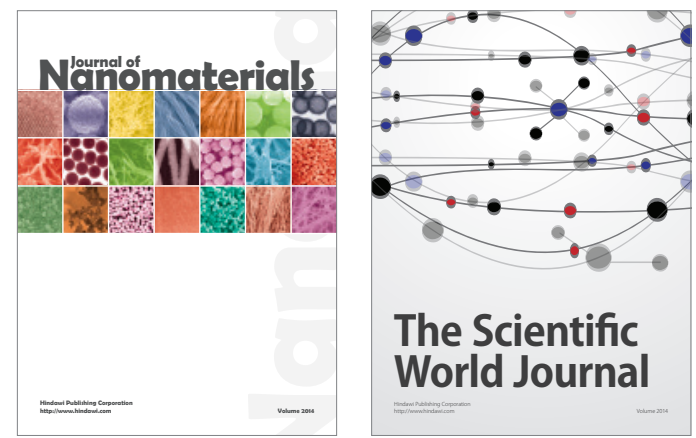

The Scientific World Journal
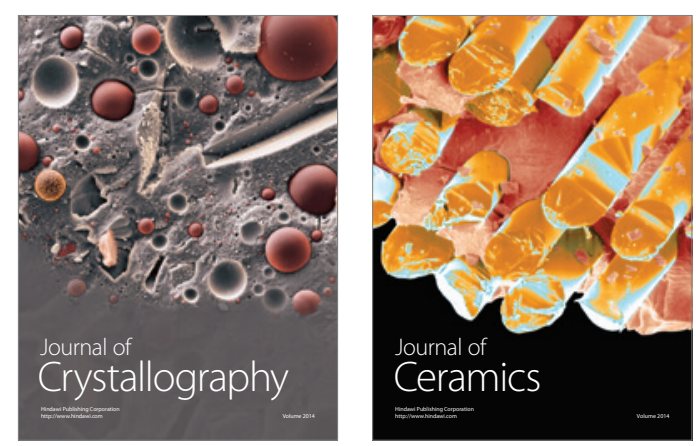
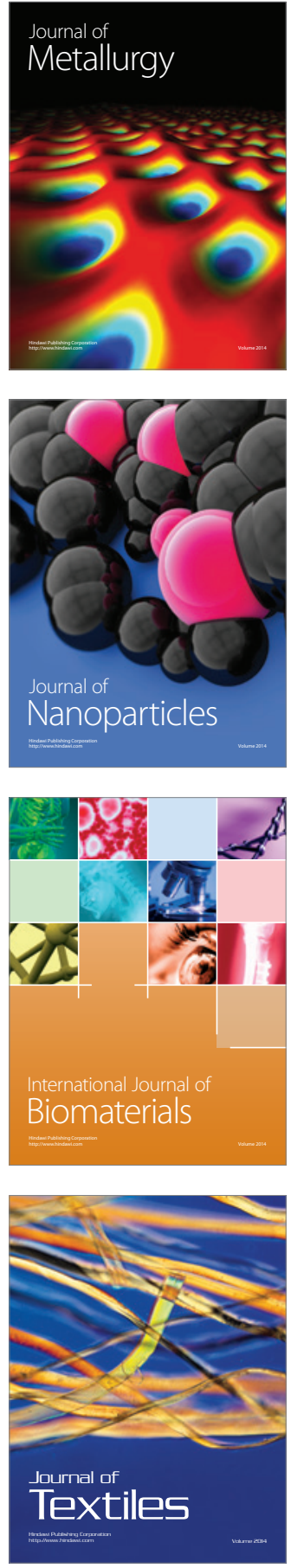